\title{
Characterization of a thermal decomposition chemical ionization mass spectrometer for the measurement of peroxy acyl nitrates (PANs) in the atmosphere
}

\author{
W. Zheng ${ }^{1,2}$, F. M. Flocke ${ }^{1}$, G. S. Tyndall ${ }^{1}$, A. Swanson ${ }^{1,2,{ }^{*} \text {, J. J. Orlando }}{ }^{1}$, J. M. Roberts ${ }^{3}$, L. G. Huey ${ }^{4}$, and \\ D. J. Tanner ${ }^{4}$ \\ ${ }^{1}$ Atmospheric Chemistry Division, National Center for Atmospheric Research, Boulder, Colorado, USA \\ ${ }^{2}$ Coorperative Institute for Research in Environmental Science, University of Colorado, Boulder, Colorado, USA \\ ${ }^{3}$ Chemical Sciences Division, Earth System Research Lab, National Oceanic and Atmospheric Administration, \\ Boulder, Colorado, USA \\ ${ }^{4}$ School of Earth and Atmospheric Science, Georgia Institute of Technology, Atlanta, Georgia, USA \\ *now at: Northrop Grumman Aerospace Systems, Redondo Beach, California, USA
}

Received: 31 January 2011 - Published in Atmos. Chem. Phys. Discuss.: 11 March 2011

Revised: 17 June 2011 - Accepted: 22 June 2011 - Published: 8 July 2011

\begin{abstract}
This paper presents a detailed laboratory characterization of a thermal dissociation chemical ionization mass spectrometer (TD-CIMS) for the atmospheric measurement of Peroxyacetyl nitrate (PAN) and its homologues (PANs). PANs are efficiently dissociated in a heated inlet and the resulting peroxy acyl radicals are reacted with $\mathrm{I}^{-}$ions in a flow tube. The mass spectrometer detects the corresponding carboxylate ions. PAN, peroxypropionyl nitrate (PPN), peroxyisobutyryl nitrate (PiBN), peroxy-n-butyryl nitrate $(\mathrm{PnBN})$, peroxyacryloyl nitrate (APAN), peroxycrotonyl nitrates (CPAN) and peroxymethacryloyl nitrate (MPAN) were cross-calibrated with both a dual channel GC/ECD and a total odd-nitrogen $\left(\mathrm{NO}_{\mathrm{y}}\right)$ instrument for the NCAR TD-CIMS' typical aircraft operation conditions. In addition, the instrument sensitivity to a number of more exotic PANs (peroxyhydroxyacetyl nitrate, methoxyformyl peroxynitrate, and peroxybenzoyl nitrate) was evaluated qualitatively by comparisons with a long-path FTIR instrument.

The sensitivity for PPN is slightly higher than that of PAN. Larger aliphatic and olefinic PAN compounds generally showed lower sensitivities. We postulate that these differences are owing to secondary reactions in the thermal decomposition region, which either reduce the yield of peroxy acyl radicals or cause losses of these radicals through intramolecular decomposition. The relative importance of these secondary reactions varies considerably between different PAN species.
\end{abstract}

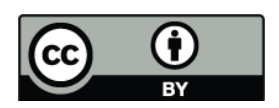

Correspondence to: F. M. Flocke (ffl@ucar.edu)
Results also indicate that the reaction of the larger peroxy acyl radicals with the ion-water cluster, $\mathrm{I}^{-}\left(\mathrm{H}_{2} \mathrm{O}\right)$ n proceeds about an order of magnitude faster than with $\mathrm{I}^{-}$alone, as has been observed for peroxy acetyl radicals. Sensitivity variations among the individual PAN species at very low water vapor were observed. The results call for careful evaluation of each PAN species to be measured and for each desired operating condition of a TD-CIMS instrument.

\section{Introduction}

Peroxyacyl Nitrates (PANs, $\mathrm{RC}(\mathrm{O}) \mathrm{OONO}_{2}$ ), also known as Peroxycarboxylic Nitric Anhydrides (Roberts et al., 2009), represent a unique group of secondary photochemical pollutants in the atmosphere. Peroxyacetyl nitrate (PAN, $\left.\mathrm{CH}_{3} \mathrm{C}(\mathrm{O}) \mathrm{OONO}_{2}\right)$ is the most abundant PAN species in the troposphere with typical atmospheric mixing ratios ranging from a few pptv or less in the remote marine boundary layer to several ppbv in heavily polluted urban regions (Marley et al., 2007; Roberts, 1990; Singh and Hanst, 1981). The other less abundant but frequently observed PANs include PPN, PiBN, MPAN, APAN and peroxybenzoyl nitrate (PBzN, $\left.\mathrm{C}_{6} \mathrm{H}_{5} \mathrm{C}(\mathrm{O}) \mathrm{OONO}_{2}\right)$. Many other PAN-type compounds with various carbon chain structures have also been observed, as well as synthesized in the laboratory. Roberts (2007) listed 43 known PAN homologues. They are rather stable adducts formed from reaction of $\mathrm{NO}_{2}$ with peroxyacyl $(\mathrm{PA}, \mathrm{RC}(\mathrm{O}) \mathrm{OO} \cdot)$ radicals, and are direct products of the oxidation of aldehydes $(\mathrm{RC}(\mathrm{O}) \mathrm{H})$ or ketones $\left(\mathrm{R}^{\prime} \mathrm{C}(\mathrm{O}) \mathrm{R}^{\prime \prime}\right)$ and indirect products of the oxidation of other volatile organic

Published by Copernicus Publications on behalf of the European Geosciences Union. 
compounds (VOCs) (Roberts, 1990). Removal processes of PAN compounds from the atmosphere are primarily photolysis in the upper troposphere and thermal decomposition in the lower troposphere, with minor contributions from chemical reactions with $\mathrm{OH}$ or $\mathrm{Cl}$ radicals (Talukdar et al., 1995). The thermal decomposition rate is highly temperature dependent, with lifetimes ranging from about 30 minutes at $298 \mathrm{~K}$ to $8 \mathrm{~h}$ at $273 \mathrm{~K}$. At temperatures characteristic of the middle and upper troposphere, the lifetime of PAN can be on the order of months (Kirchner et al., 1999; Kirchner et al., 1997). This makes PAN and some of its homologues important reservoirs of $\mathrm{NO}_{\mathrm{x}}\left(\mathrm{NO}\right.$ and $\left.\mathrm{NO}_{2}\right)$ and a significant, and often dominant, fraction of reactive nitrogen throughout much of the remote troposphere (Singh and Hanst, 1981). Understanding the chemistry and distribution of PANs is then essential to build a predictive model of global oxidants. Also since the photochemistry that produces PANs also leads to tropospheric ozone, the determination of the concentration of different PANs can provide useful information about the characteristics of hydrocarbon emissions and their impact on the ozone budget (Roberts et al., 1998; Williams et al., 1997) Thus, measuring PAN type compounds accurately is very important to the understanding of tropospheric photochemistry at various scales.

Measurements of PAN and its homologues have most often been accomplished by gas chromatography with electron capture detection (GC/ECD) (e.g., Flocke et al., 2005; Müller and Rudolph, 1989; Schrimpf et al., 1995; Singh and Salas, 1983; Volz-Thomas et al., 2002; Whalley et al., 2004), which is currently the best developed and most proven method. However, ECD signals can be significantly affected by oxygen and water, and have potential interference from other high-electron affinity compounds such as halogenated compounds and organic nitrates that may elute close to the PANs. So detectors other than ECD, such as luminol-chemiluminescence detectors (Gaffney et al., 1998) and negative ion chemical ionization-mass spectrometers (NICI-MS) (Tanimoto et al., 1999), have also been successfully employed. In general, the GC methods have low temporal resolution and are not well suited for aircraft observations or flux measurements. Methods that do not rely on chromatographic separation may have faster time response, and include thermal dissociation - laser induced fluorescence (TD-LIF) (Day et al., 2002), and proton transfer reactionmass spectrometry (PTR-MS) (Hansel and Wisthaler, 2000; de Gouw et al., 2003). The TD-LIF method measures thermally produced $\mathrm{NO}_{2}$ from organic nitrates and differentiates subsets of nitrates using different dissociation temperatures. It is only able to measure the sum of all PAN compounds and is thus unable to capture the distribution of PANs. The PTR-MS method is a chemical ionization mass spectrometry method that has found wide use in the analysis of oxygenated hydrocarbons or hydrocarbons with proton affinities higher than water. It has a comparatively fast sampling rate ( $\sim 15 \mathrm{~s}$ averaging time), but still suffers from relative low sensitivity $\left(10-40 \mathrm{cps} \mathrm{ppbv}^{-1}\right)$ and the interference from acetone-dependent $\mathrm{H}_{3} \mathrm{O}^{+}\left(\mathrm{CH}_{3} \mathrm{COCH}_{3}\right)$ cluster ions and backgrounds from other VOCs. Recently, a thermal dissociation-chemical ionization mass spectrometry (TD-CIMS) method was developed by Slusher et al. (2004). The method utilizes iodide anion as the primary ion to react with PA radicals that are produced from the thermal dissociation of PAN (Cox and Roffey, 1977; Hendry and Kenley, 1977; Roberts and Bertman, 1992).

$$
\begin{aligned}
& \mathrm{CH}_{3} \mathrm{C}(\mathrm{O}) \mathrm{OONO}_{2}+\mathrm{M} \rightarrow \mathrm{CH}_{3} \mathrm{C}(\mathrm{O}) \mathrm{OO} \cdot+\mathrm{NO}_{2}+\mathrm{M} \\
& \mathrm{CH}_{3} \mathrm{C}(\mathrm{O}) \mathrm{OO} \cdot+\mathrm{I}^{-} \rightarrow \mathrm{CH}_{3} \mathrm{C}(\mathrm{O}) \mathrm{O}^{-}+\mathrm{IO}
\end{aligned}
$$

The resulting acetate anion is then detected through a quadrupole mass spectrometer as a measurement of PAN. This approach takes the advantage of the high selectivity of $\mathrm{I}^{-}$, which reacts rapidly with PA radicals but very slowly with many highly abundant atmospheric species including ozone (Huey et al., 1995). Under normal flow tube operating conditions (i.e. $p \sim 20$ Torr, $T \sim 293 \mathrm{~K}$, inlet flow $\sim 1.6 \mathrm{slpm}$, reagent carrier flow $\sim 1.0 \mathrm{slpm}$ ), the reaction rate with PA radicals is about $\left(9_{-5}^{+7}\right) \times 10^{-10} \mathrm{~cm}^{3}$ molecule ${ }^{-1} \mathrm{~s}^{-1}$ (Villalta and Howard, 1996). The use of a prototype instrument for PAN measurement was extensively characterized and compared with the NCAR PAN-GC instrument described by Flocke et al. (2005) both in the laboratory and during field campaigns. The comparison demonstrated excellent sensitivity and selectivity of the TD-CIMS instrument for PAN and PPN as well as an ability to measure $\mathrm{NO}_{3}$ and $\mathrm{N}_{2} \mathrm{O}_{5}$ species (Slusher et al., 2004). The capability for fastrate sampling of this instrument has also been demonstrated in several ground based eddy covariance PAN flux studies over forest canopies (Turnipseed et al., 2006; Wolfe et al., 2009).

It is natural to infer that other PANs can be measured by the TD-CIMS technique through a similar mechanism since the chemical reactions take place at the peroxyacyl group, which is common to all PANs. It was also believed that the bond strength between the peroxy group and nitrate group is relatively independent of the nature of $\mathrm{R}$ (Roberts and Bertman, 1992), and the variation of reaction rates of different acyl peroxy radicals with $\mathrm{I}^{-}$should be minor. The TD-CIMS sensitivities for different PANs are not necessarily the same, but it was expected that the dependence on the external conditions would scale in a similar manner, so that the instrument can be characterized offline and a universal set of correction factors obtained for PAN homologues relative to a PAN standard, which is commonly used for in-situ calibration. In this work we investigate the response of the instrument to various PANs. We find that the sensitivities of the instrument depend very strongly on the structure of the molecule and the dissociation temperature. Hence, careful calibration and characterization are required. 


\section{Experimental approach}

\subsection{Instrumentation}

A diagram of the instrument is shown in Fig. 1. It consists of five sections at successively lower pressures separated by a series of orifices. The first stage is the thermal dissociation region, basically a thin walled $3 / 8$ inch O.D. $(0.8 \mathrm{~mm}$ wall thickness) PFA Teflon tube, inside of which the pressure is maintained at 140 torr by an in-line stainless steel pressure controller (MKS Instruments, model 640). To rule out potential surface reactions on stainless steel, a critical orifice made of PFA has also been tested as a replacement for the pressure controller, and no apparent difference in TD-CIMS detection sensitivity was observed for all species tested here. The last, $10 \mathrm{~cm}$ long, section of tubing immediately in front of the flow tube orifice is heated to $423 \mathrm{~K}$, measured at the outside of the PFA tubing wall. The residence time in the heated inlet at its typical flow rate of $1.6 \mathrm{slpm}$ is approximately $20 \mathrm{~ms}$. A constant mass flow is allowed through a $0.86 \mathrm{~mm}$ diameter aluminum critical orifice into the flow tube. The flow tube is maintained at constant pressure of 20 torr by a dry scroll pump (model P16, Air Squared, Inc.) with actively controlled pumping speed (normally operated at $\sim 1001 \mathrm{~min}^{-1}$ ), designed to stabilize the flowtube pressure to better than \pm 0.1 torr. The iodide anions are produced in a $10 \mathrm{mCi}\left(3.7 \times 10^{8}\right.$ Becquerel) ${ }^{210} \mathrm{Po}$ in-line ionizer (NRD, Inc. Model No. P-2021, half-life $\sim 138$ days) by dissociatively attaching a thermalized electron to $\mathrm{CH}_{3} \mathrm{I}$ molecules as they pass through the ion source in a 1 slpm diluted mixture in $\mathrm{N}_{2}(\sim 2 \mathrm{ppmv})$. The ion-molecule reactions occur over the length of the flow tube and the resulting product ions are transmitted through a $0.74 \mathrm{~mm}$ diameter aperture into a collisional dissociation chamber (CDC). The octopole is biased to 2 volts higher than the flowtube voltage to provide a collision energy around $48 \mathrm{kcal} \mathrm{mole}^{-1}$, so $\mathrm{RC}(\mathrm{O}) \mathrm{O}^{-}\left(\mathrm{H}_{2} \mathrm{O}\right)_{\mathrm{n}}$ can be effectively de-clustered. The CDC is maintained around 200 mtorr with a hybrid turbo pump (Alcatel model ATH $31+, 26-301 \mathrm{~s}^{-1}$ ), The ions are then guided through the octopole, mass filtered in the quadrupole, and detected by an electron multiplier (Ceramax $7550 \mathrm{M})$. The two final chambers, which contain the octopole and the quadrupole mass filter separated by a $3.2 \mathrm{~mm}$ diameter aperture, are pumped by $68 \mathrm{~s}^{-1}\left(\mathrm{~N}_{2}\right)$ turbo pumps (Varian V70LP). Background counts at the masses corresponding to PAN and its homologues are determined by pulling ambient air through a $2 \mathrm{~m}$ long stainless steel line filled with stainless steel wool heated to $423 \mathrm{~K}$ at flow rates of $2-51 \mathrm{~min}^{-1}$, which effectively destroys PAN species. This method (as opposed to using dry zero-air) has the advantage that the air matrix remains very similar to ambient air in the respective sampling region. In particular, humidity levels and VOC content are not altered significantly.
There are some changes of this system from Slusher's prototype for the following reasons:

1. The $9.5 \mathrm{~mm}$ diameter qudrupole set replaces the $16 \mathrm{~mm}$ diameter one in Slusher's prototype, the overall size and weight of instrument is reduced so that it can be fit into a single bay aircraft rack $(0.48 \mathrm{w} \times 0.53 \mathrm{~d} \times 1.07 \mathrm{~h}$ meters $)$.

2. The reduced pressure in the thermal dissociation region is chosen so that a constant dissociation condition can be sustained over the entire vertical range that an aircraft platform may sample, and was also observed to have a positive impact on the sensitivity of the instrument. This enhancement in sensitivity for PAN is likely caused by a reduction in loss from radical-radical reactions in the inlet at the lower pressure, but no quantification of this effect was performed during this study. The thermal dissociation condition is optimized to efficiently dissociate PAN into $\mathrm{NO}_{2}$ and a PA radical and minimize sensitivity fluctuations caused by temperature variations.

3. The ${ }^{210}$ Po source used in the current TD-CIMS instrument is smaller in geometry and less intense, which allows for a much smaller mass flow of $\mathrm{N}_{2}$ carrier gas (allowing a smaller gas cylinder on the aircraft) while keeping a roughly equivalent reagent ion current.

4. An octopole set replaces the stack lenses in Slusher's CDC chamber design. The octopole does not only accelerate but also collimate the ion beam. This new design was shown previously to increase the throughput of the ion beam by at least a factor of 2 .

5. The ATH $31+$ pump replaces the molecular drag pump used in the prototype. It decreases the CDC pressure by a factor of 3 and is smaller/lighter than the drag pump. The lower pressure in the CDC also allows an increase in orifice size between the CDC and the octopole region, stage 4 , from $1 \mathrm{~mm}$ to $2 \mathrm{~mm}$ diameter that roughly tripled the ion throughput to the mass spectrometer. The ATH31+ pump is also used as a backing pump for the turbo pumps and is itself backed by the inlet pump. This setup eliminates an additional oil pump (as used in the prototype) which saves 50 pounds of weight and lowers the power consumption of the instrument by about $350 \mathrm{~W}$.

6. An in-situ calibration system using an isotope labeled photolytic source (Flocke et al., 2005; Roiger et al., 2011) is integrated into this system. This photolytic source has been extensively modified for aircraft use compared to the design available commercially (Metcon, Inc.) and has been thoroughly described by Flocke et al. (2005). The only difference is that a known amount isotopically labeled ${ }^{13} \mathrm{C}_{3}$-acetone instead of ${ }^{12} \mathrm{C}_{3}$-acetone is used to produce ${ }^{13} \mathrm{C}_{2}$-PAN (TD-CIMS 


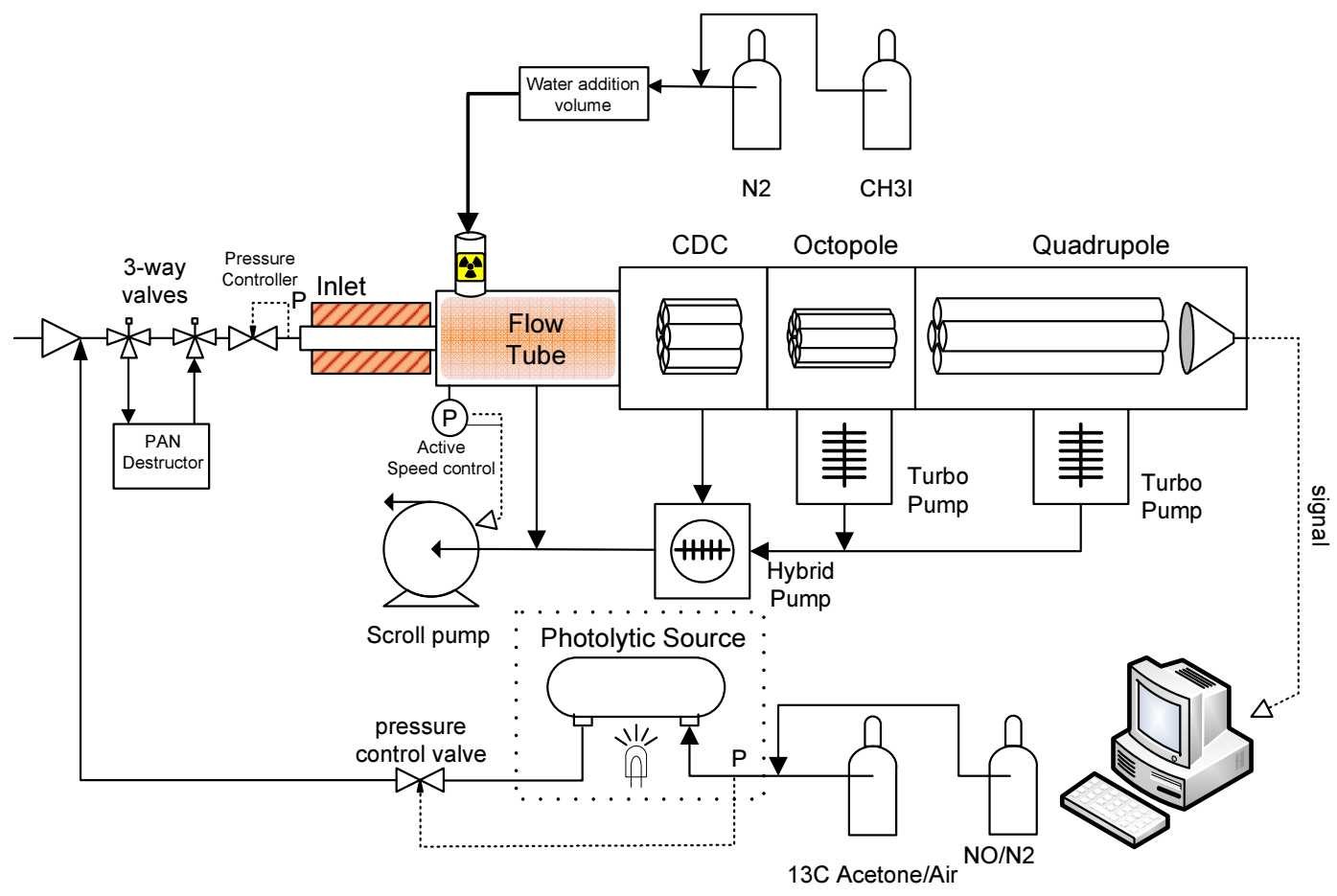

Fig. 1. Diagram of TD-CIMS. CDC $=$ Collision Dissociation Chamber. The turbo pumps are Varian, Inc. model V70LP, The hybrid pump is an Adixen model ATH31+, and the Scroll pump is an Air Squared, inc. $1001 \mathrm{~min}^{-1}$ model. A water addition volume is placed inline with the reagent gas, to ensure that the instrument sensitivity does not depend on ambient humidity. The PAN standard is produced in a photolytic source and fed into the inlet for in-situ calibrations.

signal at $m / z=61$ ) that is added into the inlet. A detailed characterization of our source is presented later in this paper. A water addition volume is placed inline of $\mathrm{N}_{2} / \mathrm{CH}_{3}$ I mixture before the radioactivity source so that changes in ambient humidity do not impact the sensitivity.

\subsection{Reference instruments}

Absolute calibration of PAN species from the calibration system was accomplished using the $\mathrm{NO}_{\mathrm{y}}$ channel of the NCAR 4-channel $\mathrm{NO}_{\mathrm{xy}}-\mathrm{O}_{3}$ instrument (CLD) and the NCAR FastPAN-GC (GC). The CLD is based on the chemiluminescence method (Ridley and Howlett, 1974) and was built in-house mainly for aircraft use. For $\mathrm{NO}_{\mathrm{y}}$ detection, the sample flow stream is mixed with about $3 \%$ carbon monoxide and passed through a heated $(573 \mathrm{~K})$ gold tube converter (Bollinger et al., 1983) to reduce the NOy species, including all PAN compounds, selectively to $\mathrm{NO}$, which is subsequently measured by chemiluminescence. $\mathrm{NO}_{2}$ in the sampling air is converted to NO in a UV photolysis cell and subsequently detected by the same mechanism. This allows for the detection of $\mathrm{NO}$ and $\mathrm{NO}_{2}$ contaminants in all of the calibration sources. The conversion efficiency of the gold tube converter was determined routinely using a known amount of $\mathrm{NO}_{2}$, which is generated by gas-phase titration of a NIST traceable NO standard with $\mathrm{O}_{3}$. Conversion efficiency for the PAN homologues to NO was assumed to be similar to that of $\mathrm{NO}_{2}$, which was consistently $80 \pm 1 \%$ during this study. The GC is a compact dual channel capillary gas chromatograph equipped with a common sampling loop and a common ECD detector and has been described thoroughly by Flocke et al. (2005). This instrument was configured for the measurement of PAN and PPN every $1.5 \mathrm{~min}$ and APAN, PiBN and MPAN every $2.5 \mathrm{~min}$. The same gas mixture was sampled by the GC and the TD-CIMS simultaneously, and the signal strengths relative to that of PAN seen by TD-CIMS for different PANs compounds were used to calculate the corresponding sensitivities of the TD-CIMS. This simultaneous sampling greatly increases the reliability of the calibration.

We also used a Fourier Transform Infrared (FTIR) spectrometer (BOMEM DA 3.01, Hanst-type multipass optics with an optical path length of $32.6 \mathrm{~m}$ ) (Shetter et al., 1987), to quantify the concentration of PAN in the environmental chamber during the chamber study. The spectral range of this FTIR spectrometer is $800-3900 \mathrm{~cm}^{-1}$ with $1 \mathrm{~cm}^{-1}$ resolution. Typically, about 200 scans were taken and added to achieve the necessary sensitivity (acquisition time 3-4 min). The chamber and FTIR system have been used extensively for laboratory studies of the photochemical formation of PANs and other species as well as their chemical properties (Wallington et al., 2001; Orlando and Tyndall, 2002; Orlando et al., 2002) Quantification was achieved using 
absorption cross sections from the literature where available (PAN, (Tsalkani and Toupance, 1989); MPAN, (Orlando et al., 2002); APAN, (Orlando and Tyndall, 2002)).

\subsection{Preparation of the PANs samples}

The major difficulty for a reliable calibration scheme is to generate a known concentration of samples with adequate purity. In this section several different methods for preparing PAN samples are presented and the possible impurities or interferences associated with each specific source and the separation methods are discussed.

\subsubsection{Photolytic source}

This method is specifically used to prepare PAN only; it utilizes the $285 \mathrm{~nm}$ photolysis of acetone in the presence of $\mathrm{O}_{2}$ to produce PA radicals. A small, calibrated flow $(1-2 \mathrm{sccm})$ of 0.5-2.0 ppmv NO in $\mathrm{N}_{2}$ is added to the gas stream and efficiently and quantitatively converted to $\mathrm{NO}_{2}$ by $\mathrm{HO}_{2}$ and $\mathrm{RO}_{2}$ (formed successively following the photolysis of an excess of acetone) and then to PAN (Pätz et al., 2002; Warneck and Zerbach, 1992). The photolytic reactions were carried out in a $200 \mathrm{~cm}^{3}$ quartz cell operated at a flow rate of $50 \mathrm{sccm}$ of zero air containing 20 ppmv of acetone (Scott-Marrin, Inc). The output of the photolytic source was checked with $\mathrm{NO}_{y}$ detector and the $\mathrm{NO}$ and $\mathrm{NO}_{2}$ channels of CLD. The reported average PAN yield of $95.5 \pm 2 \%$ mainly depends on the temperature of the reaction vessel, due to thermal decomposition (Flocke et al., 2005). A stable yield of $93 \%$ was observed for 2 photolytic sources attached to the TD-CIMS throughout this experiment.

A comparison of photolytic PAN calibration sources using ${ }^{12} \mathrm{C}_{3}$ - and ${ }^{13} \mathrm{C}_{3}$ - acetone was performed between the TDCIMS and the CLD to verify the conversion efficiency of the photolytic source. Equal amounts of standard NO flow from the same (in-house calibrated) cylinder were fed into photolytic cells with ${ }^{12} \mathrm{C}_{3}$-acetone and ${ }^{13} \mathrm{C}_{3}$ - acetone respectively, the output from these two photolytic PAN calibration sources was measured by the TD-CIMS, and the $\mathrm{NO}_{2}$ was determined by the $\mathrm{NO}_{2}$ channel of CLD. The results (Table 1) showed the conversion efficiency to be equivalent between both ${ }^{12} \mathrm{C}_{3}$ - and ${ }^{13} \mathrm{C}_{3}$-acetone. Interestingly, deuterated acetone $\left(\mathrm{CD}_{3} \mathrm{C}(\mathrm{O}) \mathrm{CD}_{3}\right)$ did not yield a conversion efficiency from the photo source higher than $85 \%$, probably caused by impurities in the educt.

No detectable impurities were found in the output of these photosources in either the TD-CIMS or GC; it is an excellent way to produce a very pure PAN calibration flow with an accurate concentration. Because of its robustness, and its proven track record for aircraft and ground measurements conducted over the last few years both with our instrument and others (Roiger et al., 2011), we have used this photolytic cell as the benchmark for the rest of the calibrations in this work. However, the generation of other PANs with the same photolytic mechanism is not very straightforward.
Table 1. Comparison of TD-CIMS sensitivity to ${ }^{12} \mathrm{C}_{2}$ - and ${ }^{13} \mathrm{C}_{2}$ - PAN.*

\begin{tabular}{|c|c|}
\hline PAN-C & $\begin{array}{l}\text { MS Response } \\
\left(\mathrm{cts} \mathrm{pptv}^{-1}\right)\end{array}$ \\
\hline${ }^{13} \mathrm{C}_{2}$ Photolytic PAN & $8.1 \pm 0.8$ \\
\hline${ }^{12} \mathrm{C}_{2}$ Photolytic PAN & $7.9 \pm 0.8$ \\
\hline${ }^{12} \mathrm{C}_{2}$ Synthesized PAN & $8.2 \pm 0.8$ \\
\hline
\end{tabular}

* Here the same conversion efficiency of $93 \%$ is assumed for both ${ }^{12} \mathrm{C}$ and ${ }^{13} \mathrm{C}$ photolytic sources.

Volz-Thomas et al. (2002) attempted to produce a PPN calibration flow by using diethylketone instead of acetone, but reported poor purity due to large amounts of ethyl nitrate being formed in the source. In-house tests with di-ketones have only been partially successful. Therefore, alternative preparation methods have to be explored for the higher PANs.

\subsubsection{Diffusion source}

One way of preparing PAN samples is to synthesize them in the liquid phase, namely by acid catalyzed nitration of the corresponding peroxycarboxylic acid $(\mathrm{RC}(\mathrm{O}) \mathrm{OOH})$ in tridecane $\left(\mathrm{C}_{13} \mathrm{H}_{28}\right)$ solvent. This method was originally described by Nielsen et al. (1982) and Gaffney et al. (1984), and slightly modified by Williams et al. (2000). All peroxycarboxylic acids were synthesized in situ by the oxidation of corresponding anhydrides $(\mathrm{RC}(\mathrm{O}) \mathrm{OC}(\mathrm{O}) \mathrm{R})$, except for peroxyacrylic and peroxymethacrylic acids, which were prepared by the oxidation of acryloyl or methacryloyl chloride, respectively (Bertman and Roberts, 1991; Roberts et al., 2001). In either case, the oxidation was done with $90 \% \mathrm{H}_{2} \mathrm{O}_{2}$ in an ice bath environment and the nitration was done by slow, drop-wise addition of $\mathrm{H}_{2} \mathrm{SO}_{4} / \mathrm{HNO}_{3}$ at $0{ }^{\circ} \mathrm{C}$. The final products were purified by extraction into tridecane, washed several times with ice water, and dried with anhydrous $\mathrm{MgSO}_{4}$. The samples were then kept in dry ice at $-78^{\circ} \mathrm{C}$ for storage.

To use synthesized PANs as calibration sources, a standard gas stream was generated by passing zero air over a capillary diffusion cell which contained the PAN species of interest in tridecane solution at $0^{\circ} \mathrm{C}$. The pressure of the diffusion cell was held constant by a MKS 640 pressure controller, and the output of the diffusion cell was diluted into a gas stream at a constant flow rate. The vapor pressure of tridecane is low enough ( $\sim 15$ mTorr) compared to the vapor pressure of PAN (1.98 Torr at $273 \mathrm{~K}$ (Kleindienst, 1994)) to cause no significant interference in any of the instruments. The experimental setup for the calibration of the TD-CIMS using diffusion sources for the PANs is illustrated in Fig. 2. The stability of the PANs mixing ratios produced using these cells have been shown to be very stable over several hours. We have used this method for years for ground calibrations 
and for field calibrations between flights during aircraft missions (Williams et al., 2000).

Common impurities in PANs synthesized by this method are PAN itself, $\mathrm{NO}_{2}$, the corresponding carboxylic acid and, sometimes, isopropyl nitrate. Except for the carboxylic acids, all of these impurities are sensitively detected by the NOy instrument. Carboxylic acids with stronger gas phase acidities than acetic acid can interfere in the operation of the TD-CIMS. The ${ }^{13} \mathrm{C}_{2}$ acetate ions generated from the PAN standard can act as Bronsted base reagents inside the flow tube (Harrison, 1992), abstract a proton from those carboxylic acids and generate carboxylate ions (Veres et al., 2008; Roberts et al., 2010)

$$
\mathrm{RC}(\mathrm{O}) \mathrm{OH}+\mathrm{CH}_{3} \mathrm{C}(\mathrm{O}) \mathrm{O}^{-} \rightarrow \mathrm{RC}(\mathrm{O}) \mathrm{O}^{-}+\mathrm{CH}_{3} \mathrm{C}(\mathrm{O}) \mathrm{OH}(\mathrm{R} 3)
$$

and can be misinterpreted as corresponding PANs. A preparative scale GC (prep-GC) was used to pre-separate the diffusion cell effluent prior to analysis by the TD-CIMS and CLD in order to eliminate interfering compounds. A known volume of calibration gas was injected directly onto a short, wide-bore capillary column inside a preparative scale gas chromatograph (prep-GC) which separates the PANs for discrete measurement by each system (TD-CIMS and CLD) and allows the calculation of the fraction of each impurity determined by comparison of corresponding peak areas detected by each system.

\subsection{Environmental Chamber}

PAN compounds were synthesized in an environmental chamber. Several mtorr of isopropyl nitrite (IPN) and a parent aldehyde are introduced into a 471 stainless steel chamber (Shetter et al., 1987), which is then pressurized to 800 torr with a gas mixture consisting of $80 \%$ UHP nitrogen and $20 \%$ UHP oxygen. The reaction chain is initialized with the photolysis of isopropyl nitrite by UV light (240-400 nm) from a filtered Xe-arc lamp.

$$
\begin{aligned}
& \left(\mathrm{CH}_{3}\right)_{2} \mathrm{CHONO}+\mathrm{h} v \rightarrow\left(\mathrm{CH}_{3}\right)_{2} \mathrm{CHO}+\mathrm{NO} \\
& \left(\mathrm{CH}_{3}\right)_{2} \mathrm{CHO}+\mathrm{O}_{2} \rightarrow\left(\mathrm{CH}_{3}\right)_{2} \mathrm{CO}+\mathrm{HO}_{2} \\
& \mathrm{HO}_{2}+\mathrm{NO} \rightarrow \mathrm{OH}+\mathrm{NO}_{2}
\end{aligned}
$$

The $\mathrm{OH}$ radicals then react with the aldehydes, producing the corresponding PA radicals, which subsequently react with $\mathrm{NO}_{2}$ to produce the targeted PAN compound.

$$
\begin{aligned}
& \mathrm{OH}+\mathrm{RCHO} \rightarrow \mathrm{RCO}+\mathrm{H}_{2} \mathrm{O} \\
& \mathrm{RCO}+\mathrm{O}_{2} \rightarrow \mathrm{RC}(\mathrm{O}) \mathrm{OO} . \\
& \mathrm{RC}(\mathrm{O}) \mathrm{OO} \cdot+\mathrm{NO}_{2} \leftrightarrow \mathrm{RC}(\mathrm{O}) \mathrm{OONO}_{2}
\end{aligned}
$$

The experimental setup of using the gas mixture inside the chamber as calibration source is shown in Fig. 3; about $5 \mathrm{sccm}$ gas flow is taken from the chamber through $4 \mathrm{~m}$ of
$1 / 8^{\prime \prime}$ OD Teflon tubing, controlled by a manual PFA needle valve (Galtek). Because the PANs mixing ratios in the chamber were quite high ( $100 \mathrm{~s}$ of $\mathrm{ppb})$, this flow is further diluted into a larger zero air flow (3 slpm) allowing for detection of the PANs in the CIMS instrument without saturating the detector.

To avoid having to know (and accurately control) the exact flow rates, the chamber experiments were always carried out as relative experiments with PAN as the standard. Acetaldehyde $\left(\mathrm{CH}_{3} \mathrm{CHO}\right)$ and other aldehydes $(\mathrm{RCHO})$ were introduced into the chamber at the same time, so that during the photochemical process, both PAN and its homologues were generated simultaneously. This is a sensible approach since the sensitivity of PANs relative to PAN is what we would use to calculate mixing ratios from the CIMS results in the aircraft, because we only calibrate for PAN in flight. In addition, the relative precision of the FTIR is better than the absolute measurement since many of the uncertainties or errors are common to both measurements and therefore cancel out. The relative abundance of PAN and its homologues was also determined downstream of the sampling line with the GC.

Figure 4 shows an example of the photochemical production process of PAN and APAN inside the environmental chamber as monitored by TD-CIMS. The PANs mixing ratios increase after the photolytic lamp is turned on and reach their maximum shortly after the lamp is turned off. After the mixing ratio peaks, there is an apparent slow decline. Since there is excess $\mathrm{NO}_{2}$ in the chamber, this is unlikely to be an effect related to thermal dissociation but caused by the decrease of the flow rate in the inlet line, which is a result of a slow decrease of the chamber pressure due to the sampling.

\section{Results}

\subsection{Dissociation temperature}

The feasibility of using the TD-CIMS technique to measure PANs depends on the thermal decomposition properties of each individual species. The study of the thermal decomposition of PAN started soon after PAN itself was discovered (Stephens, 1969) and the predominant mechanism has long been identified to be the homolytic bond cleavage, reaction (1) (Cox and Roffey, 1977; Bruckmann and Willner, 1983). Studies on various peroxy nitrates have also indicated that the O-N homolysis is the typical decomposition pathway for peroxynitro compounds (Graham et al., 1977; Kenley and Hendry, 1982; Niki et al., 1977; Roberts and Bertman, 1992; Spence et al., 1978). The O-N bond energy is believed to be relatively independent of the nature of $\mathrm{R}$ for PAN type molecules (Roberts and Bertman, 1992), so it is attractive to assume that the decomposition of all the PANs is proceeds in the same way, with similar thermodynamics. 


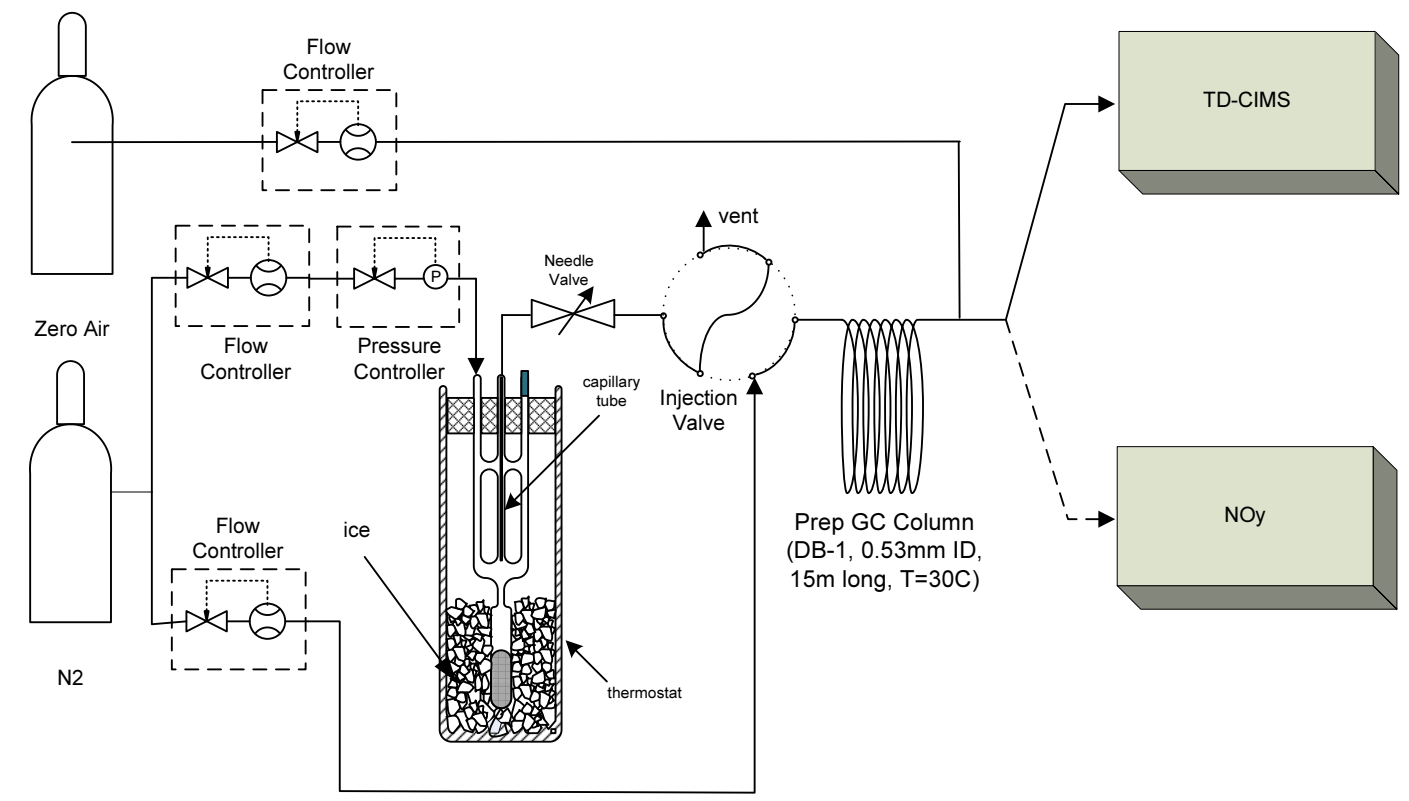

Fig. 2. Diffusion cell and preparative scale GC setup for TD-CIMS calibration.

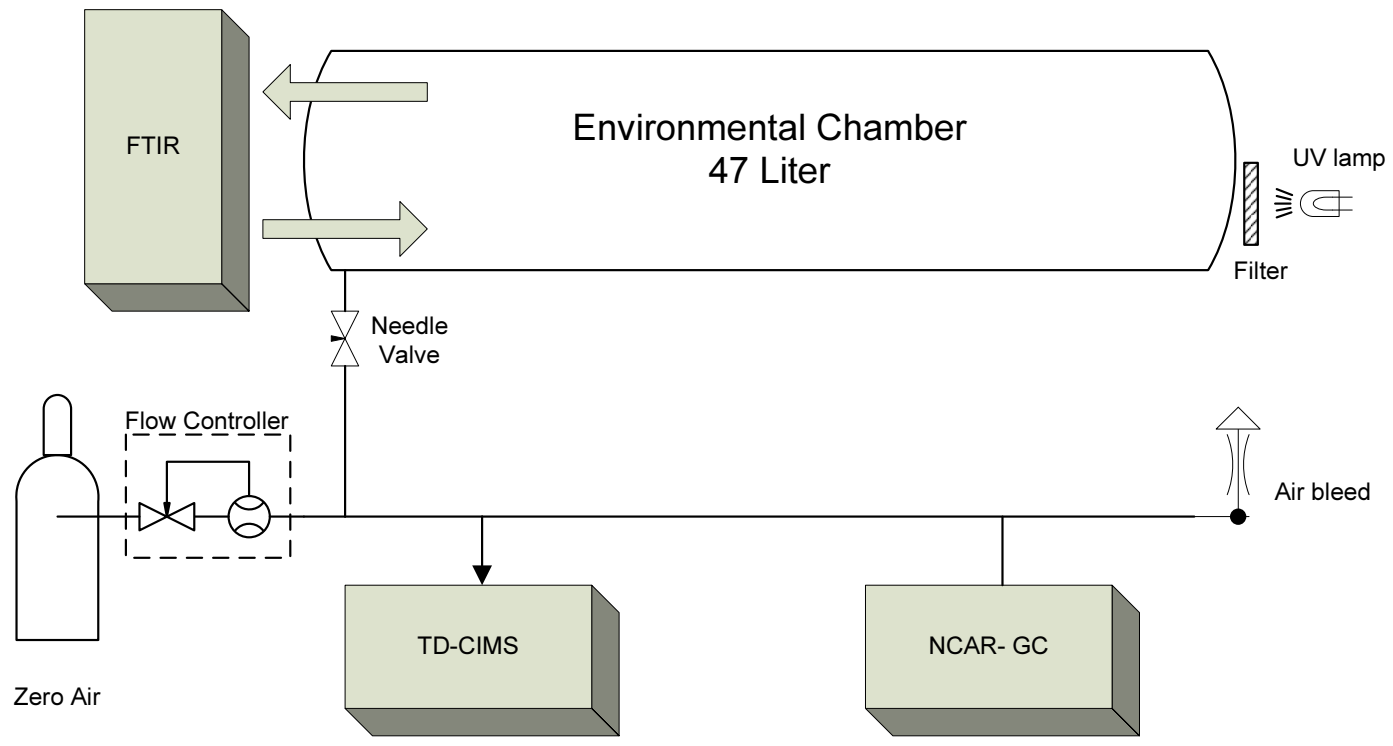

Fig. 3. Schematic of the TD-CIMS and GC measurement of PAN produced in the environmental chamber.

However, even under identical external conditions, it is not necessarily a correct assumption that all PA radicals have the same fate because the nature of $\mathrm{R}$ is expected to play a more important role here. Naturally, the PA radical lifetime becomes a concern only if they are of the same order of magnitude of or less than the transition time from the thermal dissociation region into the flow tube. There is not enough laboratory data available pertaining to PA radical kinetics for the entire spectrum of PAN species of interest to be able to evaluate this complicating factor. Therefore, experiments were carried out to investigate the temperature dependent response directly.

The experiment was done by comparing each PAN homologue's instrument response to that of PAN. The temperature of the thermal dissociation region was then varied to explore the temperature dependence of each species' sensitivity. PAN and one of its homologues were prepared simultaneously inside the chamber as described in Sect. 2.2.3. After the UV lamp is turned off, the ratio between PAN and PANs inside the chamber is fixed since the thermal lifetimes 


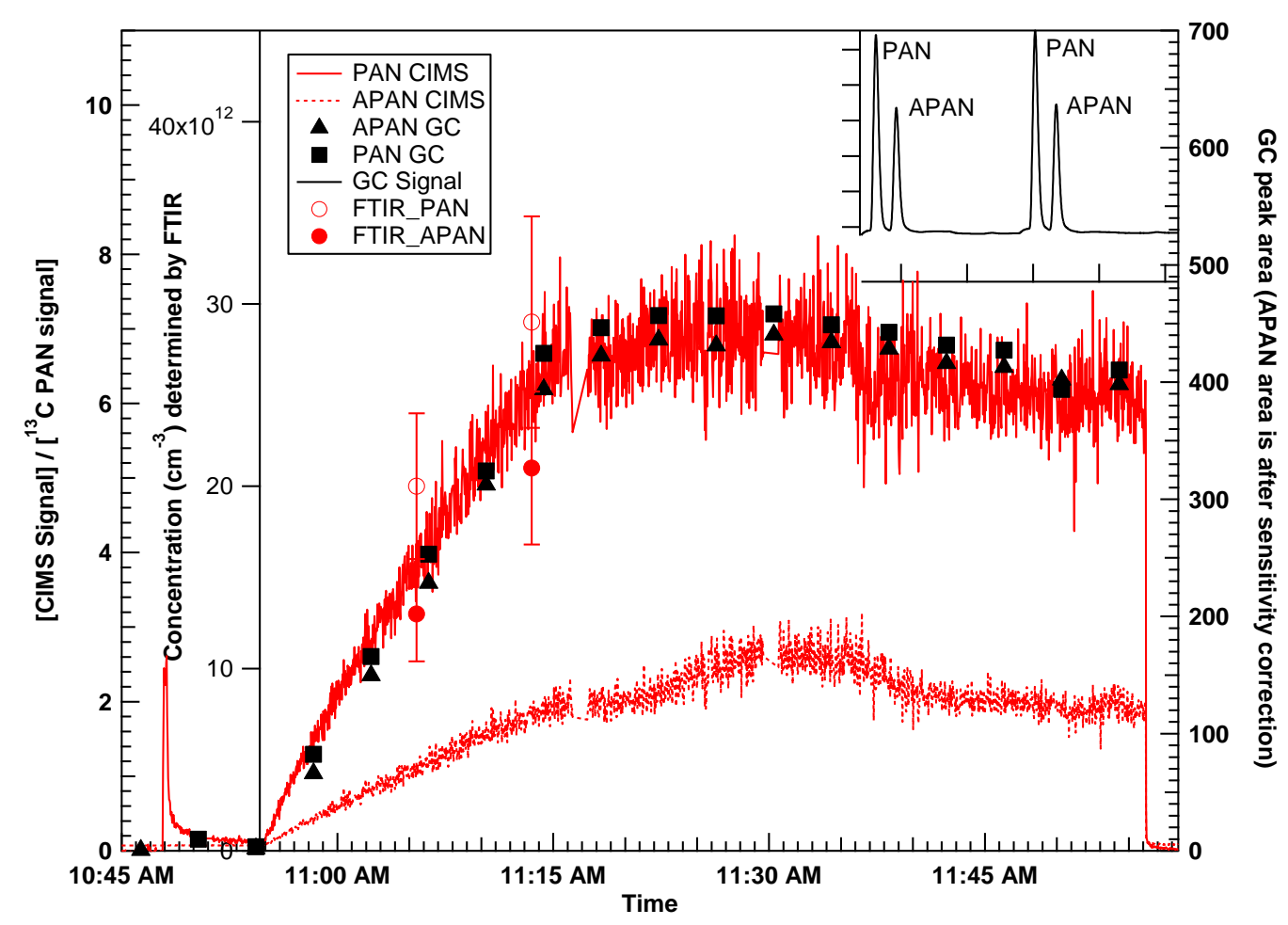

Fig. 4. An example of the real-time raw signal of a sample from the environmental chamber as seen by the TD-CIMS, NCAR Fast-GC, and the FTIR. The insert shows the chromatogram of PAN and APAN. Note that the GC sensitivity to APAN is about 0.6 times that of PAN (determined by Flocke et. al., 2005). After the GC sensitivity correction, the data agree very well (black square and triangles). The open and filled circles are the discrete FTIR measurements for PAN and APAN, respectively, with estimated measurement uncertainties.

of both species are very similar (Kirchner et al., 1997, 1999) and wall losses are negligible. This ratio was determined by FTIR and checked during the course of the experiment, and the stability of the mixing ratios inside the chamber was confirmed. A flow of the PAN mixture from the environmental chamber was then fed into the TD-CIMS and the relative signal strength of these two PAN species was recorded as a function of $T_{d}$, over the course of 10-20 min. Figure 5 shows the dependence of the APAN signal on $T_{d}$. Starting at $373 \mathrm{~K}$, it increases with $T_{d}$ and reaches a maximum at $413 \mathrm{~K}$. At higher temperatures, a dramatic decrease of the APAN signal is observed while the PAN signal increases and plateaus around $420-440 \mathrm{~K}$ and only curves down slightly above $440 \mathrm{~K}$. Other PAN species show similar behavior, as shown in Fig. 6.

We also briefly studied $\mathrm{n}-\mathrm{C}_{5} \mathrm{H}_{11} \mathrm{C}(\mathrm{O}) \mathrm{OONO}_{2}$ (HexPAN). This species shows a very low response factor. We did not attempt to quantitatively determine the response of HexPAN in this study as it is not an atmospherically important species. It should be noted that the sensitivity curves relative to PAN of the species shown in Figs. 5 and 6 do not directly correspond to the relative sensitivities recommended in Table 3 (see below). The reason for this is that the temperature ramp studies were done with a PFA orifice in place of the MKS 640 pressure controller, necessitating manually controlled inlet pressure. The inlet flow rate and pressure were thus different from our normal operating conditions, yielding slightly different relative responses at $423 \mathrm{~K}$.

To summarize, there are other processes that PA radicals undergo inside the heated inlet. Note the inlet wall temperature, inlet pressure and flow rate will determine the exact temperature profile inside the inlet and the exact residence time of the sample gas flow in the heated region. All these factors are expected to have an impact on the PA radical yields. It is therefore very unlikely that the sensitivities for all PANs relative to PAN in differently designed or operated TD-CIMS instruments would be similar, and they must be calibrated independently.

\subsection{Calibration results under standard operating conditions}

The following sections report calibrations for the suite of PAN-type compounds described above. In general, the calibration data obtained via these different approaches agree very well with each other, and thus we are confident that the method we applied can be used as a common practice before and after a field intensive to assure accurate measurements. All calibrations were carried out at an inlet flow rate of $1.6 \mathrm{slm}$, inlet pressure of 140 Torr, and a thermal dissociation temperature of $423 \mathrm{~K}$. 


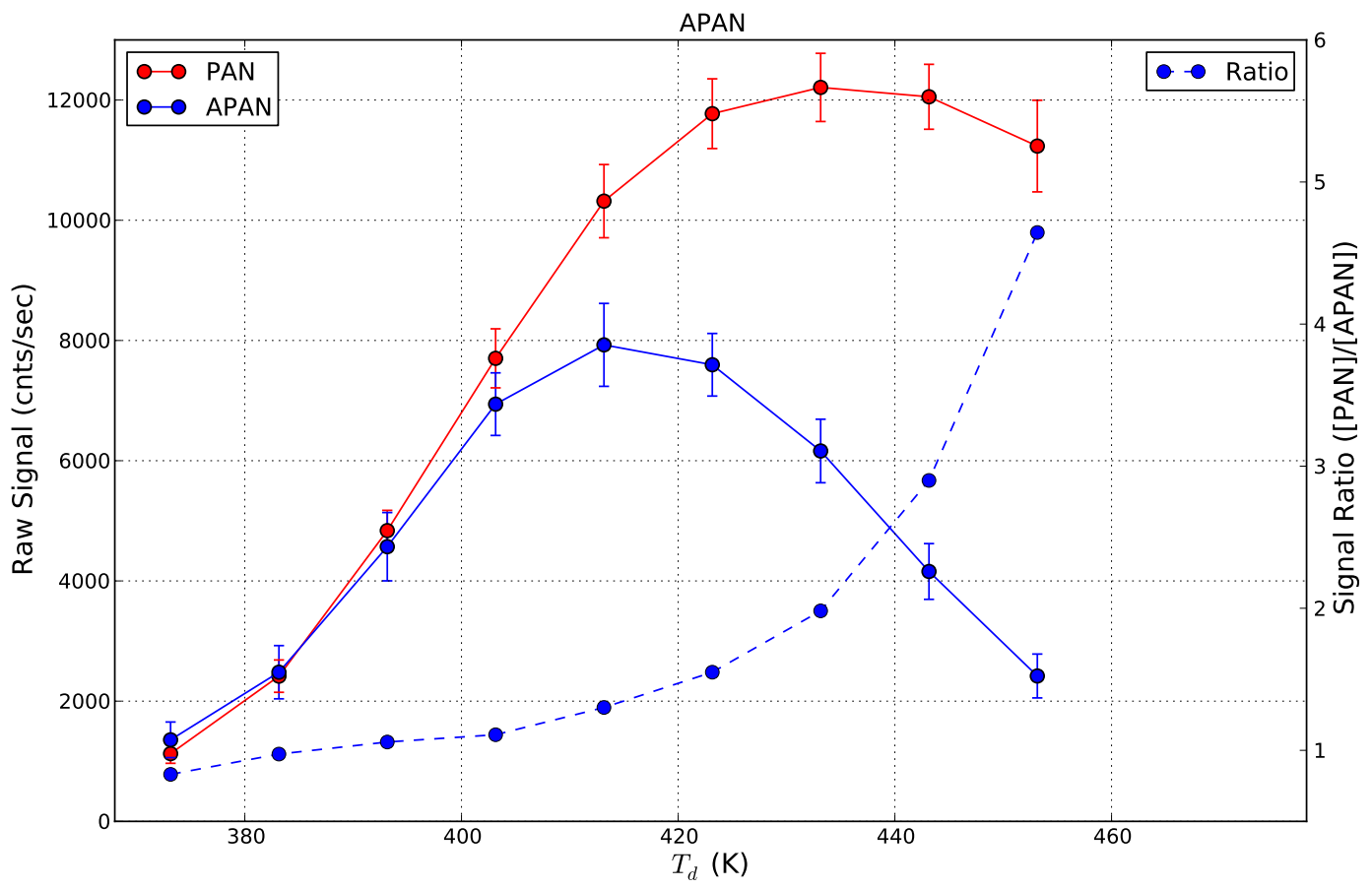

Fig. 5. The variation of the APAN signal compared to PAN as a function of the thermal dissociation temperature $\left(T_{d}\right)$.
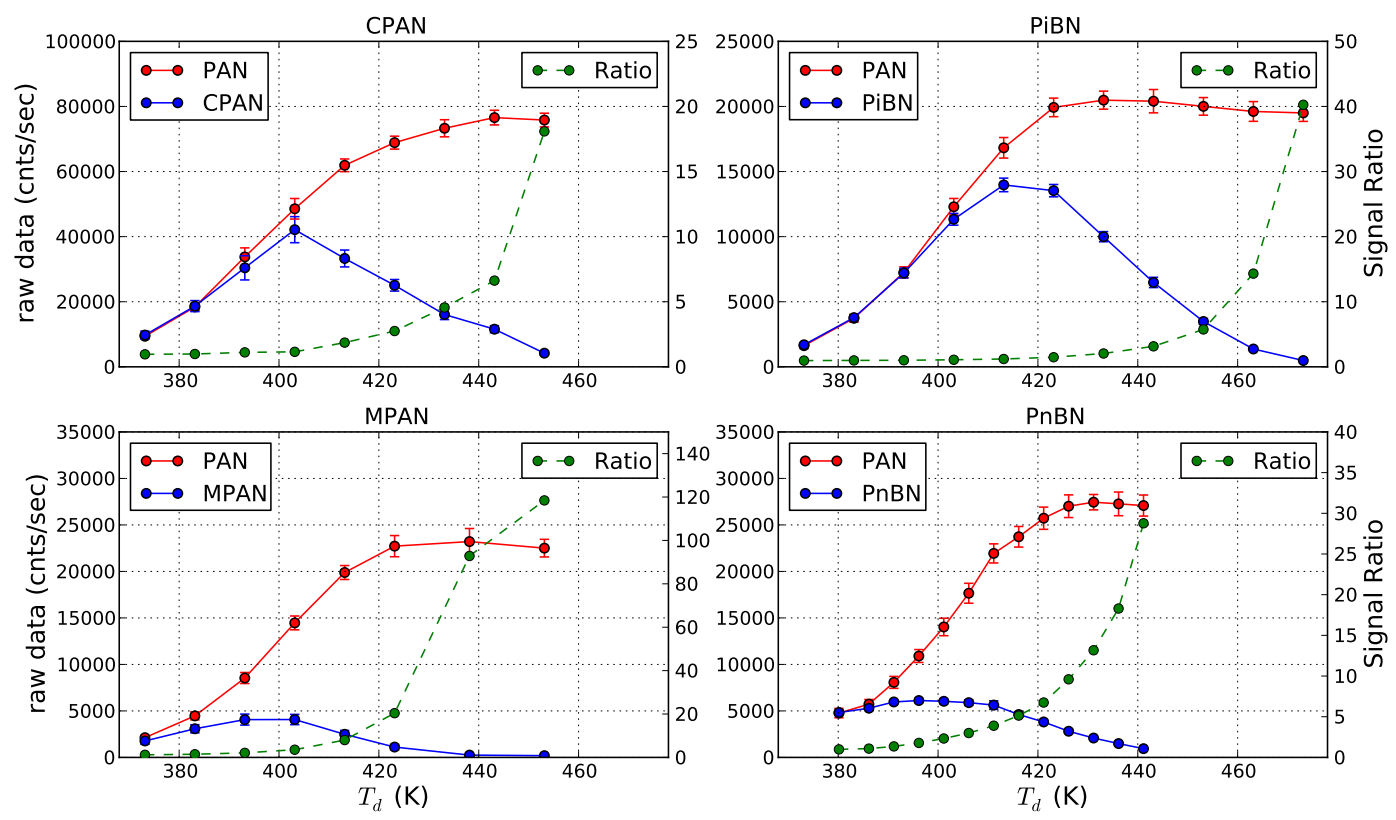

Fig. 6. The variation of $\mathrm{C}_{4}$-PAN compound signals as a function of $T_{d}$.

\subsubsection{Peroxyacetyl Nitrate: PAN}

PAN was detected as acetate ion $(m / z=59)$ in the TD-CIMS. The primary calibration for PAN was done using the ${ }^{13} \mathrm{C}_{2}$ photolytic in-situ PAN source, which also provides the basis of all the calibrations and is the basis for the comparison with the FTIR, GC and CLD. In the environmental chamber study,
PAN was produced by the oxidation of acetaldehyde by $\mathrm{OH}$ in the presence of $\mathrm{NO}_{\mathrm{x}}$. The PAN concentration measured by the TD-CIMS, calibrated with the ${ }^{13} \mathrm{C}_{2}$ photolytic source, was found to agree to within $\pm 10 \%$ of the FTIR measurements, which is well within the combined uncertainties of the two instruments. The comparison of the PAN concentration measured by TD-CIMS and the GC is plotted in Fig. 7. 
Table 2. Comparison between TD-CIMS and $\mathrm{NO}_{\mathrm{y}}$ instrument.

\begin{tabular}{llrrrr}
\hline & NOy (pptv) & TD-CIMS (pptv) & TD-CIMS/NOy & Response Factor \\
\hline & ${ }^{12}$ C Synthesized PAN \#1 & $2465 \pm 245$ & $2518 \pm 250$ & $1.02 \pm 0.14$ & \\
PAN & $2432 \pm 240$ & $2455 \pm 245$ & $1.01 \pm 0.14$ & \\
& ${ }^{12}$ C Synthesized PAN \#2 & $307 \pm 30$ & $311 \pm 30$ & $1.01 \pm 0.14$ & $1.0 \pm 0.14$ \\
& ${ }^{12}$ C Photolytic PAN & $645 \pm 65$ & $662 \pm 65$ & $1.03 \pm 0.14$ & \\
PPN & Synthesized PPN from prep GC & $60 \pm 6$ & $68 \pm 7$ & $1.13 \pm 0.16$ & $1.13 \pm 0.16$ \\
APAN & Synthesized APAN from prep GC & $177 \pm 18$ & $118 \pm 12$ & $0.66 \pm 0.10$ & $0.66 \pm 0.10$ \\
MPAN & Synthesized MPAN from prep GC & $1241 \pm 120$ & $17 \pm 2$ & $0.0137 \pm 0.002$ & $0.0137 \pm 0.002$ \\
PiBN & Synthesized PiBN from prep GC & $5763 \pm 550$ & $1060 \pm 100$ & $0.18 \pm 0.03$ & $0.18 \pm 0.03$ \\
PnBN & Synthesized PnBN from prep GC & $2001 \pm 200$ & $236 \pm 25$ & $0.12 \pm 0.02$ & $0.12 \pm 0.02$ \\
\hline
\end{tabular}

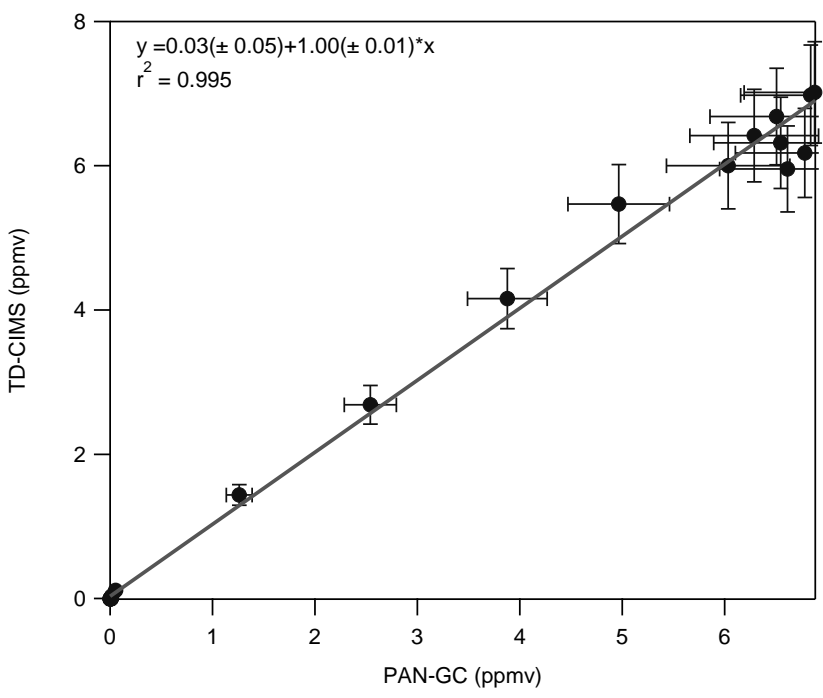

Fig. 7. Photolytically generated PAN inside the environmental chamber as measured by the TD-CIMS and the NCAR fast GC.

The bi-variant linear fit gives a slope of 1.00 with a 1 -sigma standard deviation of 0.01 . The output from the diffusion cell was coupled into the TD-CIMS and the NOy instrument either directly or through the preparative-scale GC, and the comparison is shown in Table 2 . The data show a very good correlation between them, with a difference between these instruments of less than $\pm 5 \%$. Average response factors $\mathrm{F}$ for PANs measured by the TD-CIMS relative to other techniques are given in Table 3 .

\section{3 $\mathrm{C}_{3}$ peroxyacyl nitrates: PPN and APAN}

There are two $\mathrm{C}_{3}$-peroxyacyl nitrates which have been observed in the atmosphere. The saturated compound, peroxypropionyl nitrate $\left(\mathrm{PPN} ; \mathrm{C}_{2} \mathrm{H}_{5} \mathrm{C}(\mathrm{O}) \mathrm{OONO}_{2}\right.$ ) and its unsaturated counterpart, peroxyacryloyl nitrate (APAN; $\left.\mathrm{CH}_{2}=\mathrm{CHC}(\mathrm{O}) \mathrm{OONO}_{2}\right)$.

\section{PPN}

PPN is detected as propionate ion $(\mathrm{m} / \mathrm{z}=73)$ in the TD-CIMS instrument. In the environmental chamber, PPN was produced from the $\mathrm{OH}$-initiated oxidation of propanal. We did not compare the TD-CIMS with the NCAR fast-GC for PPN measurement, but the comparison with the FTIR shows that the TD-CIMS detects PPN with a roughly $10 \%$ larger sensitivity than PAN. This result is corroborated by measurements with the NOy system, as well as comparison data between the NCAR GC and the CIMS, obtained during the PAN intercomparison exercise, conducted in Boulder in the summer of 2005 .

The PPN from the diffusion source may contain propionic acid as an impurity with a gas phase acidity of $\Delta \mathrm{G}=340.1 \mathrm{kcal} \mathrm{mole}^{-1}$ [NIST Chemistry WEBBook: http://webbook.nist.gov/chemistry/], which makes it a slightly stronger acid than acetic acid $\left(\Delta \mathrm{G}=341.5 \mathrm{kcal} \mathrm{mole}^{-1}\right)$. The proton transfer process $\mathrm{CH}_{3} \mathrm{CH}_{2} \mathrm{COOH}+\mathrm{CH}_{3} \mathrm{COO}^{-} \rightarrow$ $\mathrm{CH}_{3} \mathrm{CH}_{2} \mathrm{OO}^{-}+\mathrm{CH}_{3} \mathrm{COOH}$ is possible but may not proceed with a large reaction rate. As shown in Fig. 8, there is no apparent two-peak structure in $m / z=73$ when the PPN sample from the diffusion source was coupled into the inlet through the prep scale GC. We conclude that the higher sensitivity to PPN is real and the most likely explanation for this is a higher thermal decomposition rate for PPN than that of PAN at $423 \mathrm{~K}$, which would be consistent with the extrapolation from the experiments at room temperature (Kirchner et al., 1999; Atkinson et al., 2006), although there is no experimental data available in the literature for this temperature range. It is also possible that wall losses of the peroxypropionyl radical are slightly lower than these of PA because of the larger organic group shielding the reactive end of the molecule slightly more. 
Table 3. The response factor of TD-CIMS for different PANs (measured at an inlet pressure of 140 Torr and a temperature of $423 \mathrm{~K}$ ).

\begin{tabular}{|c|c|c|c|c|c|c|c|}
\hline & \multirow[b]{2}{*}{ FTIR } & \multirow[b]{2}{*}{ GC } & \multirow[b]{2}{*}{ CIMS } & \multicolumn{3}{|c|}{ Correction Factor } & \multirow[b]{2}{*}{ Preferred Value } \\
\hline & & & & (CIMS/FTIR) & (CIMS/GC) & $\left(\mathrm{CIMS} / \mathrm{NO}_{\mathrm{y}}\right)$ & \\
\hline PPN:PAN & 1.0 & - & 1.13 & 1.13 & $1.06^{\mathrm{a}}$ & 1.13 & $1.13 \pm 0.16$ \\
\hline APAN:PAN & 0.80 & $0.96^{\mathrm{b}}$ & 0.30 & 0.37 & 0.31 & $(0.66)^{\mathrm{c}}$ & $0.35 \pm 0.04$ \\
\hline PnBN:PAN & 1.2 & $1.35^{\mathrm{d}}$ & 0.18 & 0.15 & 0.13 & 0.12 & $0.13 \pm 0.02$ \\
\hline PiBN:PAN & 2.0 & - & 0.439 & 0.22 & - & 0.18 & $0.20 \pm 0.03$ \\
\hline MPAN:PAN & 1 & 1.02 & 0.014 & 0.014 & 0.014 & 0.014 & $0.014 \pm 0.002$ \\
\hline CPAN:PAN & 1 & - & 0.12 & 0.12 & - & - & $0.12 \pm 0.01$ \\
\hline HPAN & Exist. & - & N.A. & N.A. & N.A. & N.A. & N.A. \\
\hline
\end{tabular}

a Average value obtained during PANs intercomparison exercise, Boulder, CO, 2005 (poster presented at AGU Fall Meeting, 2005). ${ }^{\mathrm{b}}$ A response factor of 0.8 for GC was assumed here, note that as it was estimated with $\sim 20 \%$ uncertainty. ${ }^{\mathrm{c}}$ Value uncertain because of the possible presence of impurities. ${ }^{\mathrm{d}}$ Assuming the same response factor as PiBN.

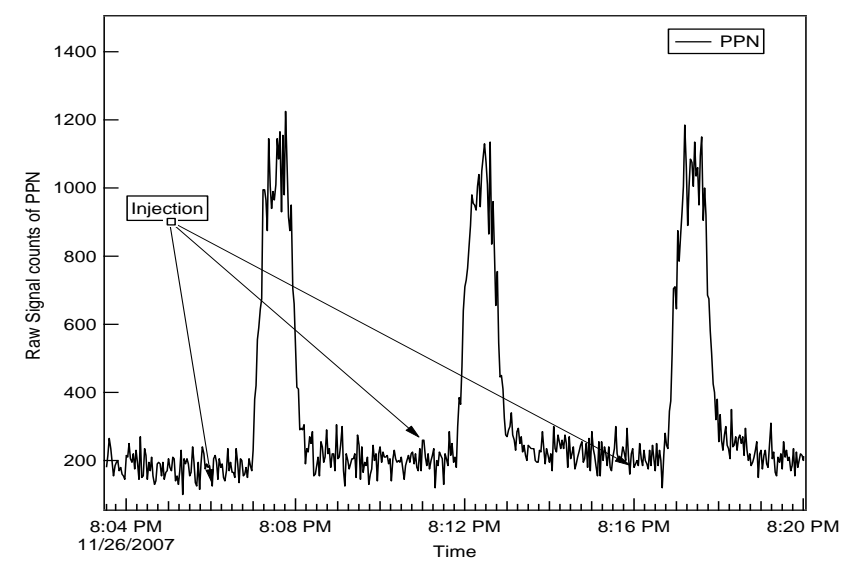

Fig. 8. Time sequence of the $\mathrm{m} / \mathrm{e}=73$ signal observed by TD-CIMS when the diffusive PPN source was coupled into the inlet through the prep-GC. No interference from propionic acid was observed.

\section{APAN}

APAN is detected as acrylate ion $(m / z=71)$ in the TD-CIMS instrument. During the environmental chamber study, PAN and APAN were produced simultaneously from the $\mathrm{OH}-$ initiated oxidation of acetaldehyde and acrolein (Orlando and Tyndall, 2002). The outflow of the chamber was then sampled in parallel by GC and TD-CIMS, as shown in Fig. 4. Figure 9a shows the GC's peak area for APAN, corrected by the reported response factor versus that of PAN in the sampling flow and Fig. 9b shows the raw counts of APAN peak to that of PAN peak in the TD-CIMS. The slopes were 0.959 (a) and 0.298 (b), respectively. Dividing the two slopes yields a sensitivity factor of the TD-CIMS's for APAN of F $=0.31$ relative to PAN. Considering the combined uncertainties of the two methods, this value agrees very well with the factor of $\mathrm{F}=0.374$, which was independently determined using the relative concentration measurement in the FTIR system.
The third factor of $\mathrm{F}=0.663$ shown in Table 3 was determined during a much earlier test where the APAN sample came from a diffusion source. The output of this source was analyzed after purification through the prep-GC with both the TD-CIMS and with the CLD. We are not as confident about this result as the diffusion source contained large amounts of impurities (the wet-chemical synthesis of APAN is very difficult and rather erratic with respect to product yields). It is likely that the prep-GC did not sufficiently separate all nitrate containing components, and we therefore prefer the value of $0.34 \pm 0.07$ for the APAN/PAN sensitivity ratio.

\subsection{1 $C_{4}$ peroxyacyl nitrates: PnBN, PiBN, MPAN and CPAN}

There are four $\mathrm{C}_{4}$ peroxyacyl nitrates of atmospheric interest: Saturated peroxy isobutyryl nitrate (PiBN; $\left.\left(\mathrm{CH}_{3}\right)_{2} \mathrm{CHC}(\mathrm{O}) \mathrm{OONO}_{2}\right)$ and peroxy n-butyryl nitrate $\left(\mathrm{PnBN} ; \quad \mathrm{CH}_{3}\left(\mathrm{CH}_{2}\right)_{2} \mathrm{C}(\mathrm{O}) \mathrm{OONO}_{2}\right)$, and unsaturated peroxymethacryloyl- (MPAN; $\mathrm{CH}_{2}=$ $\left.\mathrm{C}\left(\mathrm{CH}_{3}\right) \mathrm{C}(\mathrm{O}) \mathrm{OONO}_{2}\right)$ and peroxycrotonyl nitrate $(\mathrm{CPAN}$; $\left.\mathrm{CH}_{3} \mathrm{CH}=\mathrm{CHC}(\mathrm{O}) \mathrm{OONO}_{2}\right)$. As discussed previously in Sect. 3.1, they very likely undergo rather complex reactions in the heated thermal dissociation region even though laboratory study of the thermal decomposition of these species at room temperature has shown comparable thermal decomposition rates to that of PAN (Grosjean et al., 1994).

\section{PiBN and PnBN}

The environmental chamber study yielded TD-CIMS response factors of 0.15 for $\mathrm{PnBN}$ and $\sim 0.22$ for PiBN. The response factors of TD-CIMS to PBNs determined by FTIR were about $20 \%$ higher than those from comparison with the $\mathrm{NO}_{\mathrm{y}}$ instrument. The discrepancy is beyond the range of the combined uncertainties. This inconsistency could be partially due to the difference in lifetime of PBNs and PAN in the transfer line tubing, which could have caused a different 


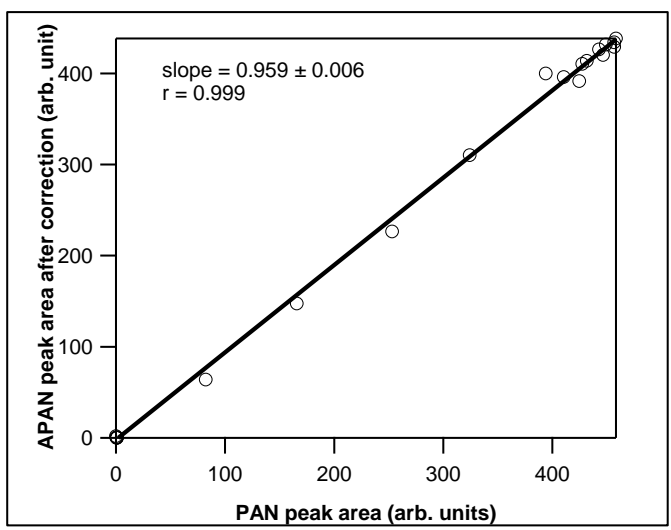

(a)

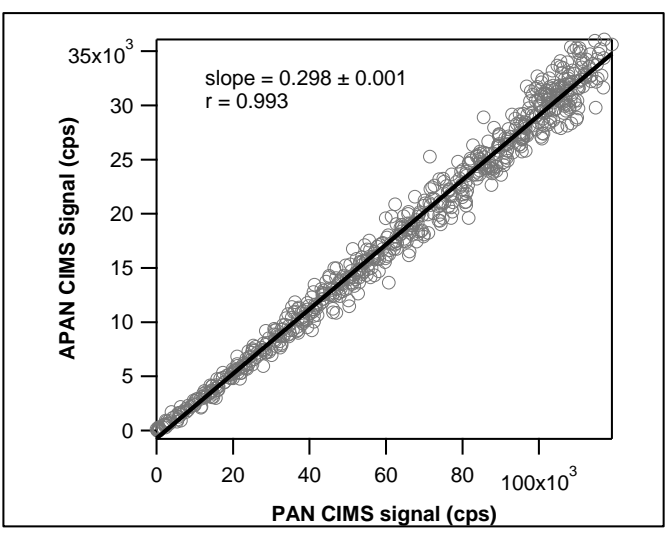

(b)

Fig. 9. APAN to PAN ratio as measured with the NCAR fast GC (a) and the TD-CIMS (b) respectively. The TD-CIMS response factor for APAN was computed by comparing these two ratios. Other PAN species response factors were determined in the same way.

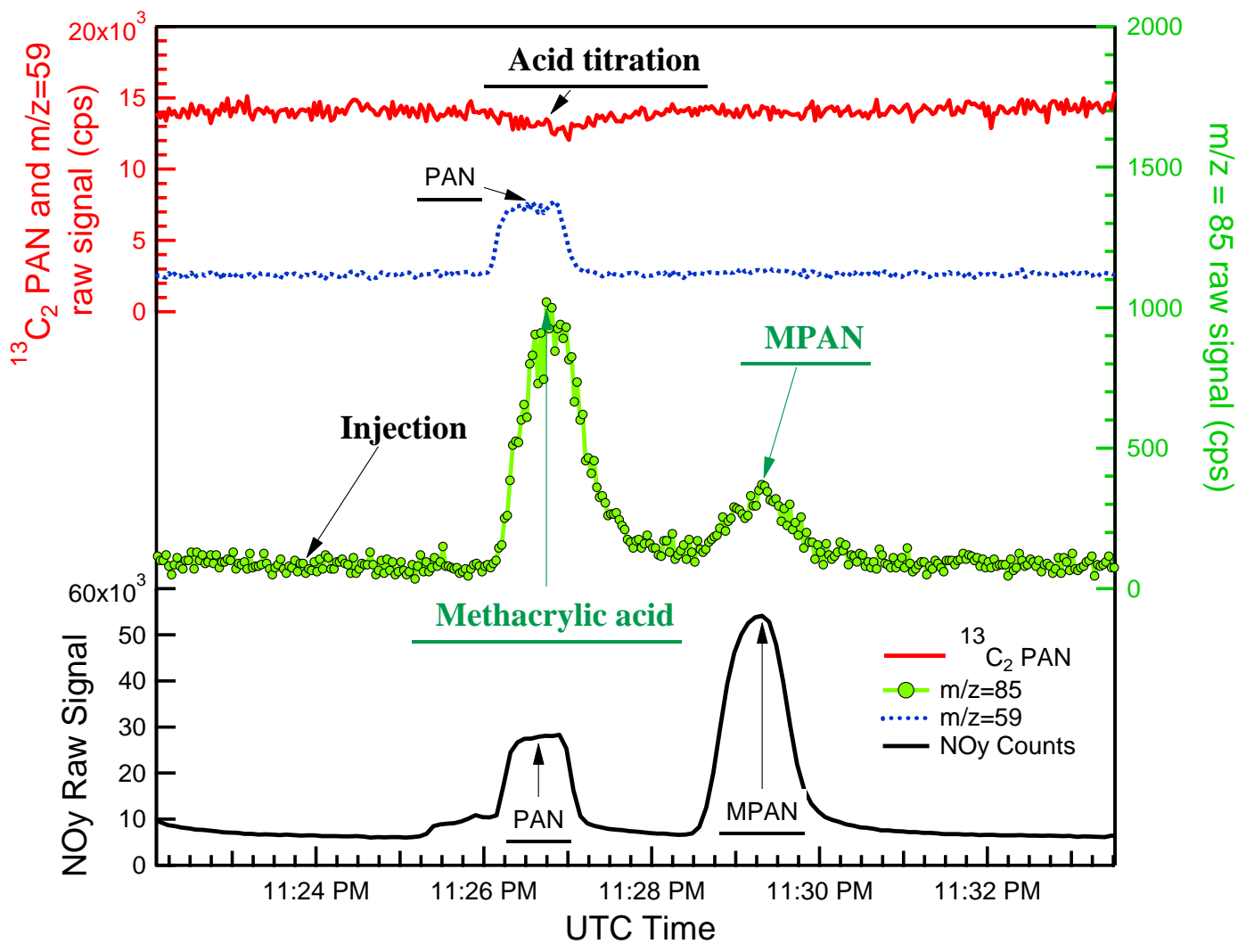

Fig. 10. MPAN as output from the prep-GC measured by the TD-CIMS and the $\mathrm{NO}_{\mathrm{y}}$ detector. The ${ }^{13} \mathrm{C}_{2}$ PAN trace shows the titration effect of the proton transfer reaction between the ${ }^{13} \mathrm{C}_{2}$ acetate ion and methacrylic acid.

PBN to PAN ratio at the inlet of the TD-CIMS than inside the chamber. For the one case where we did a direct comparison of PnBN between the NCAR fast GC and the TD-CIMS sampling simultaneously downstream of the sampling valve, the difference was smaller. Since the NOy and TD-CIMS shared a transfer line, this result should be more reliable than the FTIR data.

\section{MPAN}

MPAN is detected as methacrylate ion at $m / z=85$ in the TD-CIMS instrument. In the environmental chamber study, MPAN was produced via the $\mathrm{OH}$ initiated oxidation of methacrolein and an almost equal amount of PAN was produced as reference gas. The GC has a relative response 
factor of about 0.64 for MPAN/PAN as described by Flocke et al. (2005; Grosjean et al., 1994). Using this factor, the GC peak areas for PAN and MPAN confirmed a PAN/MPAN ratio in the chamber of very close to $1: 1$. A linear fit for the plot of TD-CIMS signals at $m / z=85$ vs. $m / z=59$ gave a slope of 0.014 , which indicated that the sensitivity of the TD-CIMS for MPAN is about 70 times less than that of PAN.

Intercomparisons using a MPAN diffusion source delivered to the prep-GC followed by measurements on the TDCIMS and NOy instruments (Fig. 2) yielded very similar results. There are a number of interferences to consider using this method. Firstly, there was a significant amount of methacrylic acid (a byproduct in MPAN preparation process) in the liquid sample. Secondly, some isopropyl nitrate and $\mathrm{NO}_{2}$ were also present in the liquid sample, causing an increased signal in the $\mathrm{NO}_{\mathrm{y}}$ instrument. A prep-GC separation was used to separate the interfering compounds from both measurements. A typical time series seen by TD-CIMS is shown in Fig. 10. The prep GC can separate the MPAN from the impurities very well, and the calibration result done by comparing the prep GC output agrees very well with the chamber experiment. There are a few published sensitivity ratios of PAN/MPAN in the literature, ranging from 4.3 to about 7 (LaFranchi et al., 2009; Wolfe et al., 2009; Slusher et al., 2004). While these larger ratios could, in part, be due to temperature and flow/pressure conditions in the thermal dissociation region that are different from the instrument used here, it is more likely that the presence of methacrylic acid in the calibration gas is a factor as well. In our instrument, a PAN/MPAN ratio of 10 or less is not achieved until the dissociation temperature is reduced to below $380 \mathrm{~K}$, where PAN is no longer efficiently dissociated.

This very low sensitivity to MPAN makes it very difficult to accurately measure MPAN in the troposphere at the levels previously observed with our GC instrument (up to a few hundred ppt over polluted, forested areas with significant isoprene emissions). The relative sensitivity can be increased by lowering $T_{d}$ to values around $393 \mathrm{~K}$, but the problem with the interferences remains.

\section{CPAN}

We had no knowledge about the sensitivity of the GC to CPAN, so we did not perform the intercomparison between TD-CIMS and NCAR fast-GC for this compound. The FTIR measured a one to one ratio for CPAN to PAN in the environmental chamber, a linear fit of $\mathrm{m} / \mathrm{z}=85$ to $\mathrm{m} / \mathrm{z}=59$ of the TDCIMS signal as a function of changing concentration showed that the TD-CIMS detects CPAN about 8 times less sensitive than PAN but about 10 times more sensitive than MPAN. Possible explanations for this observed difference between the MPAN and CPAN sensitivities could be differences in either the thermal dissociation of the $\mathrm{RC}(\mathrm{O}) \mathrm{OO}$ - radical or the reaction cross section with $\mathrm{I}^{-}$reagent ion.

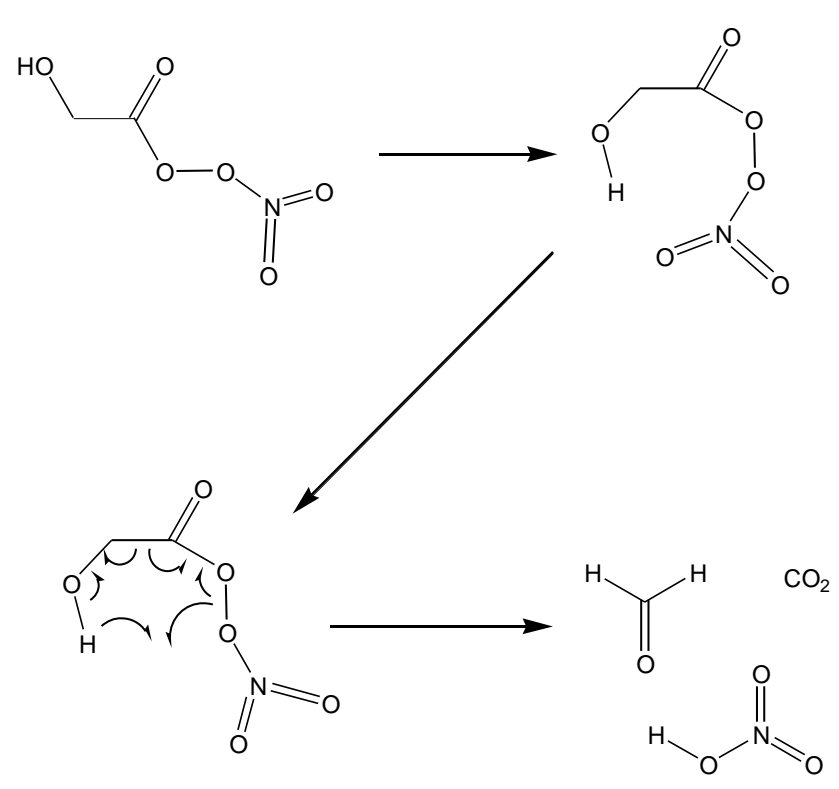

Fig. 11. Possible unimolecular thermal dissociation pathway for HPAN.

\subsubsection{Phenyl-substituted peroxyacyl nitrates}

Peroxybenzoyl nitrate $\left(\mathrm{PBzN} ; \mathrm{C}_{6} \mathrm{H}_{5} \mathrm{C}(\mathrm{O}) \mathrm{OONO}_{2}\right)$ is the simplest phenyl-substituted peroxyacyl nitrate, and is formed from the oxidation of benzaldehyde $\left(\mathrm{C}_{6} \mathrm{H}_{5} \mathrm{C}(\mathrm{O}) \mathrm{H}\right)$, a petrochemical end product in itself but more dominant in the atmosphere as a byproduct of the oxidation of toluene $\left(\mathrm{C}_{6} \mathrm{H}_{5} \mathrm{CH}_{3}\right)$. In the TD-CIMS, the peroxybenzoyl nitrate is measured as benzoate ion at $m / z=121$. Peroxybenzoyl nitrate was produced in the chamber by oxidation of benzaldehyde. It was found that heating the transfer line from the chamber to the TD-CIMS to about $30^{\circ} \mathrm{C}$ was necessary to achieve an accurate quantitative comparison for $\mathrm{C}_{6} \mathrm{H}_{5} \mathrm{C}(\mathrm{O}) \mathrm{OONO}_{2}$ against the FTIR; however, even at $30^{\circ} \mathrm{C}$ the equilibration time with the transfer lines was very long. The sensitivity of the TD-CIMS to PBzN was found to be similar to PAN, but accurate ambient measurements might be compromised by inlet line effects. This may be partially responsible for the fact that we have not yet observed significant amounts of $\mathrm{PBzN}$ in ambient air. For this reason we are unable to provide a preferred value for the relative response for PBzN.

\subsubsection{Mass 75}

An appreciable signal at $m / z=75$ was observed using the TD-CIMS during measurements of ambient air in Atlanta GA and during the NEAQS 2004 study. There are two possible candidates for that mass, peroxyhydroxyacetyl nitrate (HPAN; $\mathrm{HOCH}_{2} \mathrm{C}(\mathrm{O}) \mathrm{OONO}_{2}$ ) or methoxyformyl peroxynitrate ("MethoxyPAN" or "MoPAN"; $\left.\mathrm{CH}_{3} \mathrm{OC}(\mathrm{O}) \mathrm{OONO}_{2}\right)$. HPAN's photochemical precursor would be glycolaldehyde 
$\left(\mathrm{HOCH}_{2} \mathrm{C}(\mathrm{O}) \mathrm{H}\right)$, a by-product of methyl vinyl ketone (and hence, isoprene) oxidation. MoPAN can be formed via the oxidation of methyl formate $\left(\mathrm{HC}(\mathrm{O}) \mathrm{OCH}_{3}\right)$ (Tyndall et al., 2004; Wallington et al., 2001; Kirchner et al., 1997). Methyl formate is used primarily in the chemical industry to manufacture formamide, dimethylformamide and formic acid. It is also used as an insecticide and to manufacture certain pharmaceuticals.

We studied the behavior of HPAN, which was produced in the environmental chamber through the oxidation of glycolaldehyde, using $\mathrm{OH}, \mathrm{Cl}$ or $\mathrm{Br}$ as the oxidants, in separate experiments. However, no evidence of HPAN (i.e. $m / z=75$ ) was observed in the TD-CIMS. While other reasons like line surface losses (see also Sect. 3.4.2) and ion chemistry reasons cannot be ruled out, it is likely that an efficient uni-molecular decomposition mechanism illustrated in Fig. 11 is responsible for the inability to detect HPAN, because this mechanism would not result in radical formation. The transition state is a sterically favorable 6-membered ring and the efficiency of this mechanism is corroborated by the observed short lifetime of the HPAN in the FTIR chamber at room temperature of only 2-3 min, along with production of $\mathrm{HCHO}$ and $\mathrm{HNO}_{3}$. A similarly rapid loss of HPAN in chamber experiments was reported in the literature (Niki et al., 1981).

Oxidation of $\mathrm{CH}_{3} \mathrm{OC}(\mathrm{O}) \mathrm{H}$ was carried out in the chamber via the photolysis of $\mathrm{CH}_{3} \mathrm{ONO}$ in the presence of $\mathrm{NO}$ in $\mathrm{O}_{2} / \mathrm{N}_{2}$ balance. In contrast to HPAN, the detection efficiency of $\mathrm{CH}_{3} \mathrm{OC}(\mathrm{O}) \mathrm{OONO}_{2}$ by the TD-CIMS appears to be similar to that for PAN, which makes it likely that the $m / z=75$ signal observed in the troposphere is indeed due to MoPAN. A quantitative cross calibration of TD-CIMS against the $\mathrm{NO}_{\mathrm{y}}$ detector is still needed for a practical field application; the primary technical challenge will be the synthesis of MoPAN samples in the laboratory.

\subsection{Influence of ambient humidity}

It is well known that absolute humidity has an impact on the detection sensitivity of the TD-CIMS to PAN (Slusher et al., 2004). In this work, the humidity dependence for the measurement of PAN, PPN, PnBN and MPAN was investigated by varying the water vapor mixing ratio in the TD-CIMS inlet. In separate sets of experiments, equivalent flow tube water mixing ratios were produced by addition through the inlet or the ion source, which allowed separation of inlet effects from chemical ionization effects. Results were found to be independent of the location of the water addition, indicating that water vapor primarily impacts the chemical ionization process as reported by Slusher et al. (2004) The sensitivity of the TD-CIMS to the ${ }^{13} \mathrm{C}$ isotopically labeled PAN as a function of flow tube water vapor mixing ratio is presented in Fig. 12. The trend line shown illustrates the sharp dropoff of sensitivity below about 1000 ppmv water vapor mixing ratio. The sensitivity showed no significant dependence on water vapor mixing ratio in the flowtube above $2500 \mathrm{ppmv}$

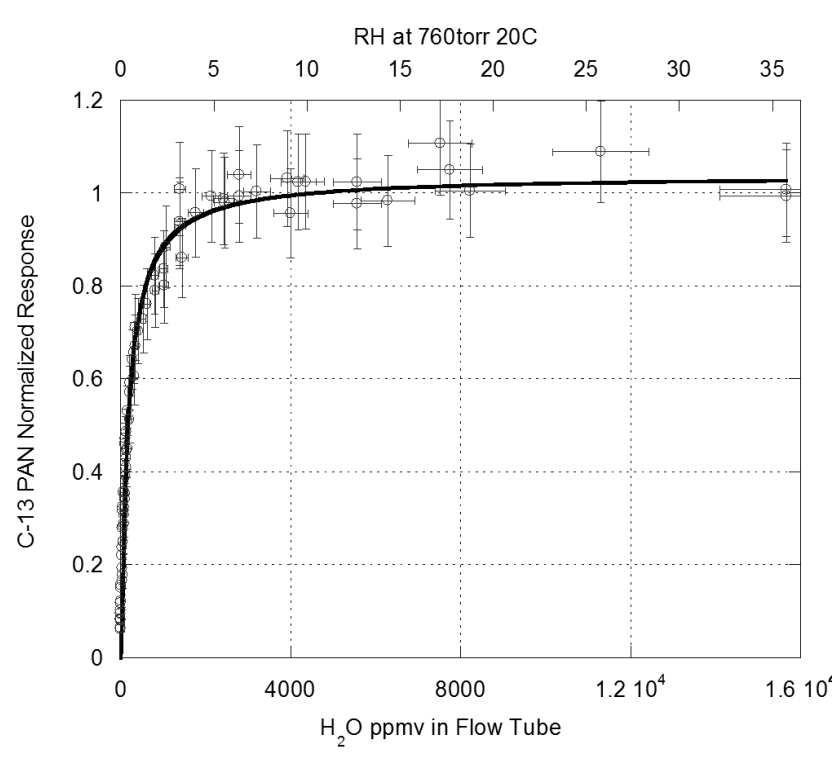

Fig. 12. The sensitivity of the TD-CIMS instrument to ${ }^{13} \mathrm{C}$ PAN as a function of absolute water concentration in the flow tube. Individual PAN measurements are shown as open circles with error bars of $10 \%$. The curve is a hyperbolic fit to the data.

( $\sim 5 \% \mathrm{RH}$ at room temperature and pressure). The sensitivity to water did not depend on inlet water content in any experiments except for MPAN where a slight increase was seen, which might be due to an unknown effect of the water on the decomposition mechanism.

The tests with PPN, MPAN and PnBN demonstrated very similar responses to that of PAN with a decrease in sensitivity at low water concentrations. However at very dry conditions $\left(<100 \mathrm{ppmv}_{2} \mathrm{O}\right)$ the loss in sensitivity was less significant (Fig. 13) for these species relative to PAN. The response factors for PPN and PnBN under extremely dry conditions ( $\sim 2$ ppmv $\left.\mathrm{H}_{2} \mathrm{O}\right)$ were roughly 3 and 5 , respectively. Relative to the response under saturated conditions, the PAN sensitivity decreases to $0.068 \pm 0.006$ at the driest $\mathrm{H}_{2} \mathrm{O}$ mixing ratios $(\sim 2 \mathrm{ppmv})$, while PPN, PnBN, and MPAN reach $0.18 \pm 0.008,0.32 \pm 0.02$ and $0.11 \pm 0.03$, respectively.

These results indicate that the detection of these PAN species has a strong humidity dependence that is dominated by processes in the flow tube. One likely explanation of these results is that the reactions of peroxy radicals with hydrated $\mathrm{I}^{-}\left(\mathrm{I}^{-}\left(\mathrm{H}_{2} \mathrm{O}\right)_{\mathrm{x}}\right)$ are more efficient than with $\mathrm{I}^{-}$(Slusher et al., 2004). The magnitude of this effect is appears to be somewhat different for each PAN species, as our results show. While the curve in Fig. 12 appears to be a well behaved hyperbolic function, Fig. 13 demonstrates that the behavior at very low humidity is more complex and maybe more than the above mentioned mechanism is involved. Fitting the sensitivity using ambient water vapor measurement on the aircraft (where very low water mixing ratios are encountered frequently) is not a viable option. We therefore minimize this effect by adding water vapor directly to the flow tube to 


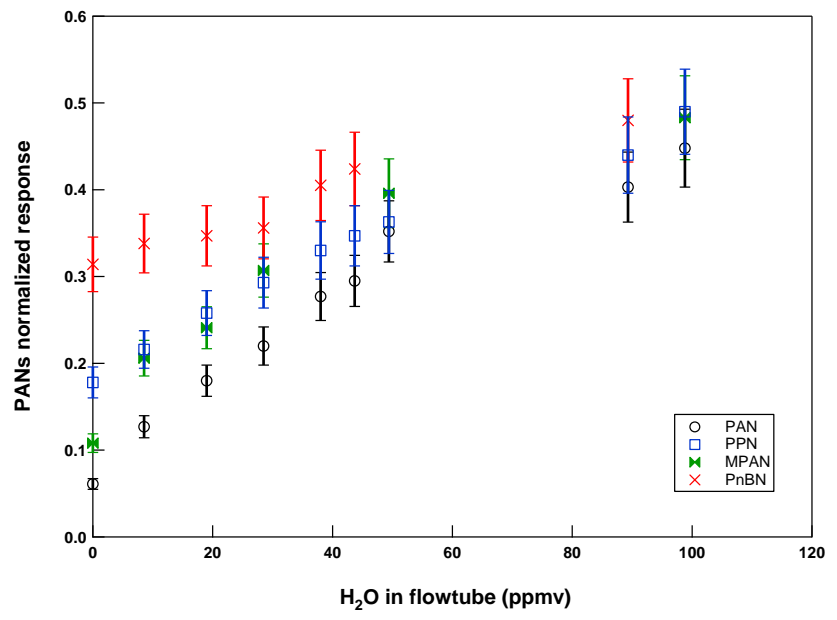

Fig. 13. Normalized sensitivity for PAN, PPN, PnBN and MPAN at low $\mathrm{H}_{2} \mathrm{O}$ mixing ratios as a function of water concentration in the flow tube.

maintain levels above 5000 ppmv at all times. When using the instrument on the ground, water addition to the flow tube is not necessary.

\subsection{Interference of in-situ calibration}

The benefit of calibration in real time is obvious. During the second Texas Air Quality Study 2006 (TexAQSII) campaign our TD-CIMS instrument was deployed on board the NOAA P3 aircraft, and during the transects of power plant plumes, the instrument was exposed to high concentrations of NO. It is well known that NO reacts with PA radicals very rapidly and this reaction can take place inside the heated inlet and the flow tube. Not surprisingly, as shown in Fig. 14, there were drops in the raw PAN signal during these transects. At the same time, the real time calibration signal also experienced the same decrease due to reaction with NO, so it can be used to calibrate out the NO effect as long as the titration is still in the linear range.

The down side of this calibration scheme is the potential artifact from carboxylic acids in the sampling air as described previously. Fig. 15 shows a laboratory demonstration of this artifact, where a mixture of MPAN and methacrylic acid and other impurities was fed into the TD-CIMS. Note that switching the ${ }^{13} \mathrm{C}_{2}$ PAN standard in and out modulated the time series of the signal at $m / z=85$, which is a direct indication of the occurrence of the proton transfer reaction (R3). In a real field measurement, there may be occasions where the concentration of carboxylic acids is high enough to cause an interference, so regular and frequent modulation of the ${ }^{13} \mathrm{C}_{2}$ PAN standard flow is recommended during field measurements in such conditions to detect and correct for this artifact.

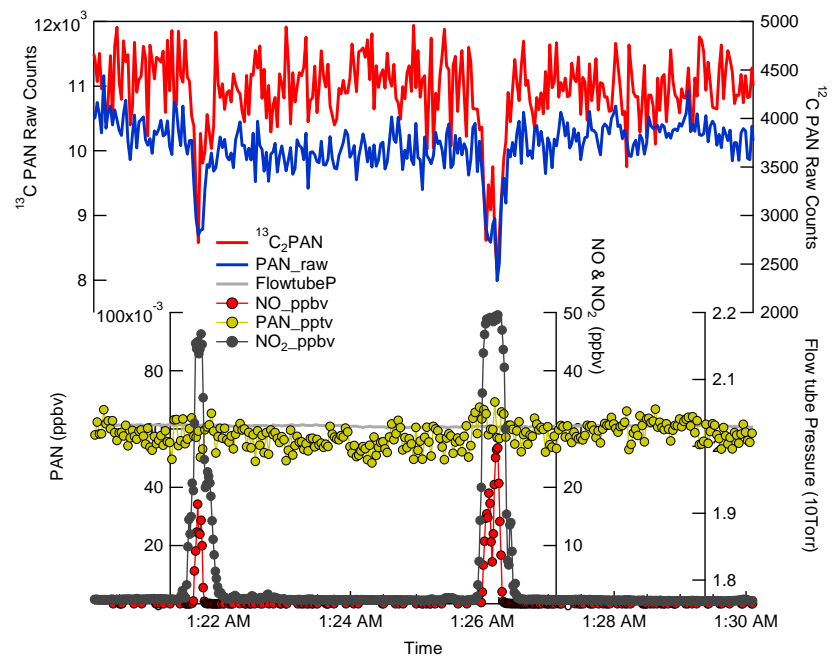

Fig. 14. Ambient NO titration effect on the TD-CIMS signal as the aircraft instrument sampled from a fresh power plant plume.

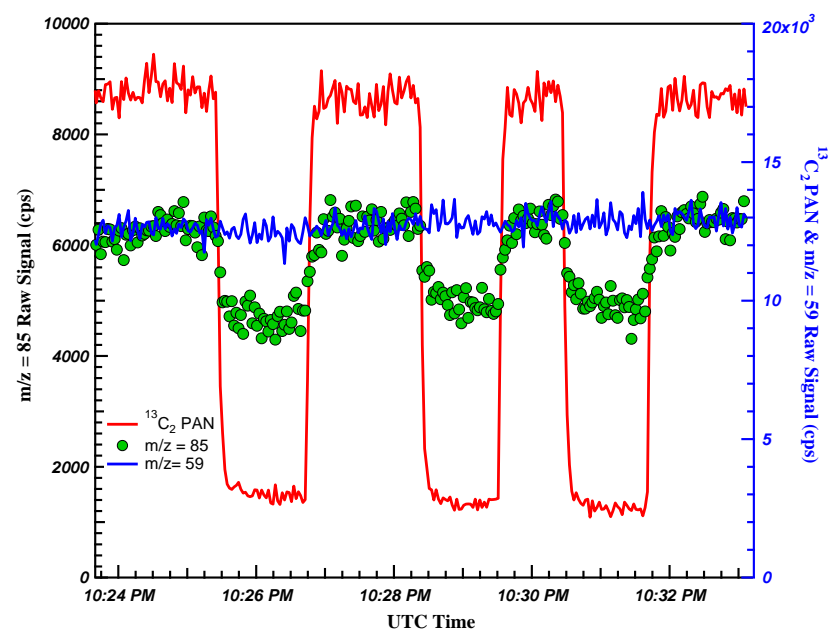

Fig. 15. Switching the ${ }^{13} C_{2}$ PAN standard in and out of the sample stream introduces modulation in the $m / z=85$ signal. This artifact on the MPAN signal is caused by proton transfer ionization of methacrylic acid by the acetate ion.

\section{Discussion}

One result of this work, and earlier studies (Slusher et al., 2004), is that the TD-CIMS exhibits substantially different sensitivities for different PANs. There are five possible reasons why the sensitivity of a given PAN could be different: alternative decomposition pathways for the PAN; decomposition of the acyl peroxy radical in the heated inlet; differences in the ion-molecule chemistry; different stability of the carboxylate anion; and differences in the mass sensitivity of the spectrometer.

The comparison between PiBN and PnBN indicates that the PA radicals with longer chains may be prone to an 
additional thermal loss process. Mass scans taken during sampling of PnBN/PAN mixture show fragmentation peaks $(m / z=41$ and 57). These fragmentation peaks are observed to increase when the PnBN signal decreases at higher $T_{d}$. Adding a small amount of $\mathrm{NO}$ into the inlet titrates both the PnBN signal and the fragments away. Since NO is known to only react with $\mathrm{C}_{3} \mathrm{H}_{7} \mathrm{C}(\mathrm{O}) \mathrm{O}_{2}$ radical but not the $\mathrm{PnBN}$ molecule, the disappearance of the fragments indicates they are formed from the peroxy radicals.

The state of knowledge about the properties and chemical behavior of longer chain peroxyacyl nitrates is limited (Roberts, 2007). Molecular orbital studies have shown that for the thermal decomposition, besides the channel producing the PA radical and $\mathrm{NO}_{2}$, there is a possibility of an O-O bond fission with nearly equal energy (R10) (Miller et al., 1999; Roberts, 2007; von Ahsen et al., 2004)

$$
\begin{aligned}
& \mathrm{RC}(\mathrm{O}) \mathrm{OONO}_{2} \rightarrow \mathrm{RC}(\mathrm{O}) \mathrm{OO} \cdot+\mathrm{NO}_{2} \\
& \mathrm{RC}(\mathrm{O}) \mathrm{OONO}_{2} \rightarrow \mathrm{RC}(\mathrm{O}) \mathrm{O} \cdot+\mathrm{NO}_{3} \\
& \mathrm{RC}(\mathrm{O}) \mathrm{OONO}_{2} \rightarrow \text { other products }
\end{aligned}
$$

Alkoxy radicals with 4 or more carbon atoms are known to isomerize at room temperature, and a similar reaction occurs for alkyl peroxy radicals at elevated temperatures (DeSain et al., 2003; Hughes et al., 1992). Under the conditions inside the heated inlet, it is then possible that the acyl peroxy radicals of sufficient length $\left(\geq \mathrm{C}_{4}\right)$ decompose in this manner, e.g.,

$$
\begin{aligned}
& \mathrm{C}_{3} \mathrm{H}_{7} \mathrm{C}(\mathrm{O}) \mathrm{O}_{2} \rightarrow \mathrm{CH}_{3} \mathrm{CHCH}_{2} \mathrm{C}(\mathrm{O}) \mathrm{OOH} \text { or } \\
& \mathrm{C}_{2} \mathrm{H}_{5} \mathrm{CHC}(\mathrm{O}) \mathrm{OOH}
\end{aligned}
$$

thus decreasing sensitivity of the TD-CIMS for measurement of the parent PAN (see Sect. 3.1).

The above mentioned reactions are also expected to be pressure dependent and the abundance of PA radicals also depends on the residence time within the heated inlet, so not only the temperature profile within the thermal dissociation region but also the inlet pressure and flow rate impact the relative sensitivity of PANs compare to PAN.

Unfortunately, at present, the use of the TD-CIMS to measure MPAN is quite problematic. Firstly, $\mathrm{CF}_{3} \mathrm{O}^{-}(\mathrm{m} / \mathrm{z}=85)$ was observed from outgassing of the heated PFA Teflon inlet tubing; this effect decreased as the tubing aged, but adds a background in mass 85 , which adversely affects the limit of detection. Secondly, there is no way to differentiate between MPAN and CPAN, and since the sensitivity to CPAN is considerably higher than that to MPAN, even relatively low concentrations of CPAN in an urban plume can make MPAN measurements questionable. Furthermore, the fundamental sensitivity to MPAN is low and varies sharply with $T_{d}$ (see Fig. 6).

\section{Summary}

A TD-CIMS instrument, based on the technique developed by Slusher et al. (2004), was thoroughly characterized for its capability to measure a number of PAN-type compounds that are important in the atmosphere. The sensitivity to each PAN-type compound was found to be highly dependent on inlet conditions, i.e. the thermal dissociation temperature, inlet pressure, and sampling flow rate, likely due to differences in the high temperature chemistry of the corresponding PA radicals. The calibration of the TD-CIMS for different PANs needs to be performed for every individual instrument and the corresponding operating conditions. A reliable calibration scheme was developed by comparing the TD-CIMS method with a FTIR, a GC/ECD, and a NOy instrument. It was demonstrated that the TD-CIMS method is able to selectively detect and precisely quantify some PANs in the atmosphere with appropriate calibration. The relative sensitivities for various PANs under the inlet conditions optimized for PAN measurement are reported: PPN with slightly higher sensitivity to that of PAN, and APAN, PBN (PiBN+PnBN), CPAN with lower sensitivity. PBzN and MoPAN are also detected by TD-CIMS, but PBzN suffered significant loss in the inlet line and a detailed quantitative determination of the sensitivity to MoPAN is still needed. Peroxymethacryloyl nitrate (MPAN) appears to be affected largely by thermal decomposition of the MPA radical in the inlet which effectively reduces its sensitivity to about $1.4 \%$ that of PAN plus the potential interferences from methacrylic acid and CPAN, renders the TD-CIMS method very limited for MPAN measurements in the field. HPAN is also not detectable in the instrument because of its short thermal lifetime and its decomposition to non-radical products, however the abundance of HPAN in the troposphere is likely not significant except in very unusual cases. Finally, the sensitivity of the chemical ionization method has significant water dependence at humidity levels equivalent to flow tube mixing ratios of less than 5000 ppmv. This effect is best eliminated by addition of water to the ion molecule region during instrument operation.

\begin{abstract}
Acknowledgements. We are grateful for the assistance provided to us at various stages of this work by Andy Neuman, Roger Hendershot, Alam Hasson, Paul Stock, and Sandra Lopes. This work was performed with support from the National Center for Atmospheric Research, which is funded by the National Science Foundation. John Orlando and Geoff Tyndall acknowledge additional support from the NASA Upper Atmosphere Research Program.
\end{abstract}

Edited by: J. N. Crowley 


\section{References}

Atkinson, R., Baulch, D. L., Cox, R. A., Crowley, J. N., Hampson, R. F., Hynes, R. G., Jenkin, M. E., Rossi, M. J., Troe, J., and IUPAC Subcommittee: Evaluated kinetic and photochemical data for atmospheric chemistry: Volume II - gas phase reactions of organic species, Atmos. Chem. Phys., 6, 3625-4055, doi:10.5194/acp-6-3625-2006, 2006.

Bertman, S. B. and Roberts, J. M.: A pan analog from isoprene photooxidation, Geophys. Res. Lett., 18, 1461-1464, doi:10.1029/91g101852, 1991.

Bollinger, M. J., Sievers, R. E., Fahey, D. W., and Fehsenfeld, F. C.: Conversion of notrogen-dioxide, nitric-acid, and normal-propyl nitrate to nitric-oxide by gold-catalyed reduction with carbonmonoxide, Anal. Chem., 55, 1980-1986, 1983.

Bruckmann, P. W. and Willner, H.: Infrared spectroscopic study of peroxyacetyl nitrate (pan) and its decomposition products, Env. Sci. Technol., 17, 352-357, 1983.

Cox, R. A. and Roffey, M. J.: Thermal decomposition of peroxyacetylnitrate in the presence of nitric oxide, Env. Sci. Technol., 11, 900-906, 1977.

Day, D. A., Wooldridge, P. J., Dillon, M. B., Thornton, J. A., and Cohen, R. C.: A thermal dissociation laser-induced fluorescence instrument for in situ detection of no2, peroxy nitrates, alkyl nitrates, and hno3, J. Geophys. Res., 107, 4046, doi:10.1029/2001JD000779, 2002.

de Gouw, J. A., Goldan, P. D., Warneke, C., Kuster, W. C., Roberts, J. M., Marchewka, M., Bertman, S. B., Pszenny, A. A. P., and Keene, W. C.: Validation of proton transfer reactionmass spectrometry (ptr-ms) measurements of gas-phase organic compounds in the atmosphere during the new england air quality study (neaqs) in 2002, J. Geophys. Res., 108(18), 4682, doi:10.1029/2003jd003863, 2003.

DeSain, J. D., Klippenstein, S. J., and Taatjes, C. A.: Time-resolved measurements of oh and ho2 product formation in pulsedphotolytic chlorine atom initiated oxidation of neopentane, Phys. Chem. Chem. Phys., 5, 1584-1592, doi:10.1039/b211452f, 2003.

Flocke, F. M., Weinheimer, A. J., Swanson, A. L., Roberts, J. M., Schmitt, R., and Shertz, S.: On the measurement of pans by gas chromatography and electron capture detection, J. Atmos. Chem., 52, 19-43, 2005.

Gaffney, J. S., Fajer, R., and Senum, G. I.: An improved procedure for high-purity gaseous peroxyacyl nitrate production - use of heavy lipid solvents, Atmos. Env., 18, 215-218, 1984.

Gaffney, J. S., Bornick, R. M., Chen, Y. H., and Marley, N. A.: Capillary gas chromatographic analysis of nitrogen dioxide and pans with luminol chemiluminescent detection, Atmos. Env., 32, 1445-1454, 1998.

Graham, R. A., Winer, A. M., and Pitts, J. N.: Temperaturedependence of unimolecular decomposition of pernitric acid and its atmospheric implications, Chem. Phys. Lett., 51, 215-220, 1977.

Grosjean, D., Grosjean, E., and Williams, E. L.: Thermal decomposition of c3-substituted peroxyacyl nitrates, Res. Chem. Intermed., 20, 447-461, 1994.

Hansel, A. and Wisthaler, A.: A method for real-time detection of pan, ppn and mpan in ambient air, Geophys. Res. Lett., 27, 895898, 2000

Harrison, A.: Chemical ionization mass spectrometry, second edi- tion, CRC Press, 1992.

Hendry, D. G. and Kenley, R. A.: Generation of peroxy radicals from peroxy nitrates $\left(\mathrm{ro}_{2} \mathrm{no}_{2}\right)$ - decomposition of peroxyacyl nitrates, J. Am. Chem. Soc., 99, 3198-3199, 1977.

Huey, L. G., Hanson, D. R., and Howard, C. J.: Reactions of $\mathrm{sf}_{6}^{-}$ and $\mathrm{i}^{-}$with atmospheric trace gases, J. Phys. Chem., 99, 50015008, 1995.

Hughes, K. J., Lightfoot, P. D., and Pilling, M. J.: Direct measurements of the peroxy hydroperoxy radical isomerization, a key step in hydrocarbon combustion, Chem. Phys. Lett., 191, 581586, 1992.

Kenley, R. A. and Hendry, D. G.: Generation of peroxy-radicals from peroxynitrates (roono2) - decomposition of peroxybenzoyl nitrate (pbzn), J. Am. Chem. Soc., 104, 220-224, 1982.

Kirchner, F., Thuner, L. P., Barnes, I., Becker, K. H., Donner, B., and Zabel, F.: Thermal lifetimes of peroxynitrates occurring in the atmospheric degradation of oxygenated fuel additives, Env. Sci. Technol., 31, 1801-1804, 1997.

Kirchner, F., Mayer-Figge, A., Zabel, F., and Becker, K. H.: Thermal stability of peroxynitrates, Int. J. Chem. Kinet., 31, 127-144, 1999.

Kleindienst, T. E.: Recent developments in the chemistry and biology of peroxyacetyl nitrate, Res. Chem. Intermed., 20, 335-384, 1994.

LaFranchi, B. W., Wolfe, G. M., Thornton, J. A., Harrold, S. A., Browne, E. C., Min, K. E., Wooldridge, P. J., Gilman, J. B., Kuster, W. C., Goldan, P. D., de Gouw, J. A., McKay, M., Goldstein, A. H., Ren, X., Mao, J., and Cohen, R. C.: Closing the peroxy acetyl nitrate budget: observations of acyl peroxy nitrates (PAN, PPN, and MPAN) during BEARPEX 2007, Atmos. Chem. Phys., 9, 7623-7641, doi:10.5194/acp-9-7623-2009, 2009.

Marley, N. A., Gaffney, J. S., Ramos-Villegas, R., and Cárdenas González, B.: Comparison of measurements of peroxyacyl nitrates and primary carbonaceous aerosol concentrations in Mexico City determined in 1997 and 2003, Atmos. Chem. Phys., 7, 2277-2285, doi:10.5194/acp-7-2277-2007, 2007.

Miller, C. E., Lynton, J. I., Keevil, D. M., and Francisco, J. S.: Dissociation pathways of peroxyacetyl nitrate (pan), J. Phys. Chem. A, 103, 11451-11459, 1999.

Müller, K. P. and Rudolph, J.: An automated technique for the measurement of peroxyacetylnitrate in ambient air at ppb and ppt levels, J. Env. Anal. Chem., 37, 253-262, 1989.

Nielsen, T., Hansen, A. M., and Thomsen, E. L.: A convenient method for preparation of pure standards of peroxyacetyl nitrate for atmospheric analyses, Atmos. Env., 16, 2447-2450, 1982.

Niki, H., Maker, P. D., Savage, C. M., and Breitenbach, L. P.: Fourier-transform ir spectroscopic observation of pernitric acid formed via hoo $+\mathrm{no}_{2}->$ hoono $_{2}$, Chem. Phys. Lett., 45, 564566, 1977.

Niki, H., Maker, P. D., Savage, C. M., and Hurley, M. D.: Fouriertransform infrared study of the kinetics and mechanisms for the cl-atom-initiated and ho-radical-initiated oxidation of glycolaldehyde, J. Phys. Chem., 91, 2174-2178, 1987.

Orlando, J. J. and Tyndall, G. S.: Mechanisms for the reactions of oh with two unsaturated aldehydes: Crotonaldehyde and acrolein, J. Phys. Chem. A, 106, 12252-12259, 2002.

Orlando, J. J., Tyndall, G. S., Bertman, S. B., Chen, W., and Burkholder, J. B.: Rate coefficient for the reaction of oh with $\mathrm{ch}_{2}=\mathrm{c}\left(\mathrm{ch}_{3}\right) \mathrm{c}(\mathrm{o})$ oono $_{2}(\mathrm{mpan})$, Atmos. Env., 36, 1895-1900, 
2002.

Pätz, H. W., Lerner, A., Houben, N., and Volz-Thomas, A.: Validation of a new method for the calibration of peroxy acetyl nitrate (pan)-analyzers, Gefahrst. Reinh. Luft., 62, 215-219, 2002.

Ridley, B. A. and Howlett, L. C.: Instrument for nitric-oxide measurements in stratosphere, Rev. Sci. Instrum., 45, 742-746, 1974.

Ridley, B. A. and Orlando, J. J.: Active nitrogen in surface ozone depletion events at alert during spring 1998, J. Atmos. Chem., 44, 1-22, 2003.

Roberts, J. M.: The atmospheric chemistry of organic nitrates, Atmos. Env., 24A, 243-287, 1990.

Roberts, J. M. and Bertman, S. B.: The thermal-decomposition of peroxyacetic nitric anhydride (pan) and peroxymethacrylic nitric anhydride (mpan), Int. J. Chem. Kinet., 24, 297-307, 1992.

Roberts, J. M., Williams, J., Baumann, K., Buhr, M. P., Goldan, P. D., Holloway, J., Hubler, G., Kuster, W. C., McKeen, S. A., Ryerson, T. B., Trainer, M., Williams, E. J., Fehsenfeld, F. C., Bertman, S. B., Nouaime, G., Seaver, C., Grodzinsky, G., Rodgers, M., and Young, V. L.: Measurements of pan, ppn, and mpan made during the 1994 and 1995 nashville intensives of the southern oxidant study: Implications for regional ozone production from biogenic hydrocarbons, J. Geophys. Res., 103, 2247322490, 1998.

Roberts, J. M., Flocke, F., Weinheimer, A., Tanimoto, H., Jobson, B. J., Riemer, D., Apel, E., Atlas, E., Donnelly, S., Stroud, V., Johnson, K., Weaver, R., and Fehsenfeld, F. C.: Observations of apan during texaqs 2000, Geophys. Res. Lett., 28, 4195-4198, 2001.

Roberts, J. M.: Pan and related compounds, in: Volatile organic compounds in the atmosphere, edited by: Koppmann, R., Blackwell Publishing Ltd, 221-268, 2007.

Roberts, J. M., Osthoff, H. D., Brown, S. S., Ravishankara, A. R., Coffman, D., Quinn, P., and Bates, T.: Laboratory studies of products of $\mathrm{n}_{2} \mathrm{O}_{5}$ uptake on $\mathrm{cl}^{-}$containing substrates, Geophys. Res. Lett., 36, L20808, doi:10.1029/2009GL040448, 2009.

Roberts, J. M., Veres, P., Warneke, C., Neuman, J. A., Washenfelder, R. A., Brown, S. S., Baasandorj, M., Burkholder, J. B., Burling, I. R., Johnson, T. J., Yokelson, R. J., and de Gouw, J.: Measurement of HONO, HNCO, and other inorganic acids by negative-ion proton-transfer chemical-ionization mass spectrometry (NI-PT-CIMS): application to biomass burning emissions, Atmos. Meas. Tech., 3, 981-990, doi:10.5194/amt-3-981-2010, 2010.

Roiger, A., Aufmhoff, H., Stock, P., Arnold, F., and Schlager, H.: An aircraft-borne chemical ionization - ion trap mass spectrometer (CI-ITMS) for fast PAN and PPN measurements, Atmos. Meas. Tech., 4, 173-188, doi:10.5194/amt-4-173-2011, 2011.

Schrimpf, W., Muller, K. P., Johnen, F. J., Lienaerts, K., and Rudolph, J.: An optimized method for airborne peroxyacetyl nitrate (pan) measurements, J. Atmos. Chem., 22, 303-317, 1995.

Shetter, R. E., Davidson, J. A., Cantrell, C. A., and Calvert, J. G.: Temperature variable long path cell for absorptionmeasurements, Rev. Sci. Instrum., 58, 1427-1428, 1987.

Singh, H. B. and Hanst, P. L.: Peroxyacetyl nitrate (pan) in the unpolluted atmosphere - an important reservoir for nitrogenoxides, Geophys. Res. Lett., 8, 941-944, 1981.

Singh, H. B. and Salas, L. J.: Peroxyacetyl nitrate in the free troposphere, Nature, 302, 326-328, 1983.

Slusher, D. L., Huey, L. G., Tanner, D. J., Flocke, F. M., and
Roberts, J. M.: A thermal dissociation-chemical ionization mass spectrometry (td-cims) technique for the simultaneous measurement of peroxyacyl nitrates and dinitrogen pentoxide, J. Geophys. Res., 109(13), D19315, doi:10.1029/2004JD004670, 2004.

Spence, J. W., Edney, E. O., and Hanst, P. L.: Peroxychloroformyl nitrate - synthesis and thermal-stability, Chem. Phys. Lett., 56, 478-483, 1978.

Stephens, E. R.: The formation, reactions, and properties of peroxyacyl nitrates (pans) in photochemical air pollution, Adv. Environ. Res., 1, 119-146, 1969.

Talukdar, R. K., Burkholder, J. B., Schmoltner, A. M., Roberts, J. M., Wilson, R. R., and Ravishankara, A. R.: Investigation of the loss processes for peroxyacetyl nitrate in the atmosphere - uv photolysis and reaction with oh, J. Geophys. Res., 100, 1416314173, 1995.

Tanimoto, H., Hirokawa, J., Kajii, Y., and Akimoto, H.: A new measurement technique of peroxyacetyl nitrate at parts per trillion by volume levels: Gas chromatography/negative ion chemical ionization mass spectrometry, J. Geophys. Res., 104, 21343-21354, 1999.

Tsalkani, N. and Toupance, G.: Infrared absorptitives and integrated band intensities for gaserous peroxyacetyl nitrate (pan), Atmos. Env., 23, 1849-1854, 1989.

Turnipseed, A. A., Huey, L. G., Nemitz, E., Stickel, R., Higgs, J., Tanner, D. J., Slusher, D. L., Sparks, J. P., Flocke, F. M., and Guenther, A.: Eddy covariance fluxes of peroxyacetyl nitrates (pans) and noy to a coniferous forest, J. Geophys. Res., 111(17), D09304, doi:10.1029/2005JD006631, 2006.

Tyndall, G. S., Pimentel, A. S., and Orlando, J. J.: Temperature dependence of the alpha-ester rearrangement reaction, J. Phys. Chem. A, 108, 6850-6856, 2004.

Veres, P., Roberts, J. M., Warneke, C., Welsh-Bon, D., Zahniser, M., Herndon, S., Fall, R., and de Gouw, J.: Development of negative-ion proton-transfer chemical-ionization mass spectrometry (ni-pt-cims) for the measurement of gas-phase organic acids in the atmosphere, Int. J. Mass. Spec., 274, 48-55, doi:10.1016/j.ijms.2008.04.032, 2008.

Villalta, P. W. and Howard, C. J.: Direct kinetics study of the $\mathrm{ch}_{3} \mathrm{c}(\mathrm{o}) \mathrm{o}_{2}^{-}+$no reaction using chemical ionization mass spectrometry, J. Phys. Chem., 100, 13624-13628, 1996.

Volz-Thomas, A., Xueref, I., and Schmitt, R.: An automatic gas chromatograph and calibration system for ambient measurements of pan and ppn, Env. Sci. Pollut. Res., 72-76, 2002.

von Ahsen, S., Willner, H., and Francisco, J. S.: Thermal decomposition of peroxy acetyl nitrate $\mathrm{ch}_{3} \mathrm{c}(\mathrm{o}) \mathrm{oono}_{2}$, J. Chem. Phys., 121, 2048-2048, 2004.

Wallington, T. J., Hurley, M. D., Maurer, T., Barnes, I., Becker, K. H., Tyndall, G. S., Orlando, J. J., Pimentel, A. S., and Bilde, M.: Atmospheric oxidation mechanism of methyl formate, J. Phys. Chem. A, 105, 5146-5154, 2001.

Warneck, P. and Zerbach, T.: Synthesis of peroxyacetyl nitrate in air by acetone photolysis, Env. Sci. Technol., 26, 74-79, 1992.

Whalley, L. K., Lewis, A. C., McQuaid, J. B., Purvis, R. M., Lee, J. D., Stemmler, K., Zellweger, C., and Ridgeon, P.: Two highspeed, portable gc systems designed for the measurement of nonmethane hydrocarbons and pan: Results from the jungfraujoch high altitude observatory, J. Env. Mon., 6, 234-241, 2004.

Williams, J., Roberts, J. M., Fehsenfeld, F., Bertman, S., Buhr, M. P., Goldan, P., Hubler, G., Kuster, W., Ryerson, T. B., Trainer, 
M., and Young, V.: Regional ozone from biogenic hydrocarbons deduced from airborne measurements of pan, ppn, and mpan, Geophys. Res. Lett., 24, 1099-1102, 1997.

Williams, J., Roberts, J. M., Bertman, S. B., Stroud, C. A., Fehsenfeld, F. C., Baumann, K., Buhr, M. P., Knapp, K., Murphy, P. C., Nowick, M., and Williams, E. J.: A method for the airborne measurement of pan, ppn, and mpan, J. Geophys. Res., 105, 2894328960, 2000.
Wolfe, G. M., Thornton, J. A., Yatavelli, R. L. N., McKay, M., Goldstein, A. H., LaFranchi, B., Min, K.-E., and Cohen, R. C.: Eddy covariance fluxes of acyl peroxy nitrates (PAN, PPN and MPAN) above a Ponderosa pine forest, Atmos. Chem. Phys., 9, 615-634, doi:10.5194/acp-9-615-2009, 2009. 